\title{
Nucleophilic 5-endo-trig Cyclization of 2-(Trifluoromethyl)allylic Metal Enolates and Enamides: Synthesis of Tetrahydrofurans and Pyrrolidines Bearing exo- Difluoromethylene Units
}

\author{
Takeshi Fujita, Masahiro Hattori, Masaaki Matsuda, Ryutaro Morioka, Tanner C. Jankins, Masahiro Ikeda \\ and Junji Ichikawa*
}

Division of Chemistry, Faculty of Pure and Applied Sciences, University of Tsukuba, Tsukuba, Ibaraki 305-8571, Japan

\section{ARTICLE INFO}

Article history:

Received

Received in revised form

Accepted

Available online

Keywords:

cyclization

fluorine

heterocycle

tetrahydrofuran

pyrrolidine

$\mathrm{C}-\mathrm{F}$ bond activation

\section{Introduction}

Fluoroalkenes constitute a class of versatile compounds not only in synthetic chemistry, but also in pharmaceutical, agricultural, and materials sciences. ${ }^{1}$ Among their uses, they serve as key building blocks for synthesizing fluorine-containing compounds via addition-elimination process. ${ }^{2-4}$ Because of their electron-deficiency, fluoroalkenes are successfully subjected to nucleophilic substitution. By utilizing the reactivity of fluoroalkenes, we developed methods for cyclizing 1,1-difluoro1-alkenes and 2-(trifluoromethyl)-1-alkenes, which were directed toward constructing fluorine-containing hetero- and carbocycles. $^{3,4}$ For example, 1,1-difluoro-1-alkenes bearing oxygen, nitrogen, sulfur, and carbon nucleophilic sites underwent intramolecular cyclization through nucleophilic vinylic substitution $\left(\mathrm{S}_{\mathrm{N}} \mathrm{V}\right)$ to afford ring-fluorinated cyclic compounds. Similarly, cyclization of 2-trifluoromethyl-1-alkenes proceeded through $\mathrm{S}_{\mathrm{N}} 2$-type reactions to afford difluoromethylene- or difluoromethyl-bearing hetero- and carbocycles. Although transformation of trifluoromethyl groups often causes complete defluorination (cleavage of all three $\mathrm{C}-\mathrm{F}$ bonds), this protocol enables single $\mathrm{C}-\mathrm{F}$ bond activation of $\mathrm{CF}_{3}$ groups. ${ }^{5,6}$

We already demonstrated that the high reactivity of fluoroalkenes induced not only 6-endo-trig cyclization but also 5endo-trig cyclization, ${ }^{3,4,7,8}$ which is disfavored according to Baldwin's rules. ${ }^{9-12}$ During the course of our studies, we recently reported nucleophilic 5-endo-trig cyclization of 3,3difluoroallylic ketones and imines (Scheme 1a). ${ }^{13}$ Selective $O$ and $N$-cyclizations proceeded successfully despite the extra steric constraint associated with the planarity of intermediary metal enolates and enamides, which afforded 2-alkylidene-2,3dihydrofurans and -dihydropyrroles, respectively. As a further challenge, we investigated nucleophilic cyclization of 2(trifluoromethyl)allylic ketones $\mathbf{1}$ and imines $\mathbf{2}$, in which the difluorovinyl groups of 3,3-difluoroallylic ketones and imines were replaced with the (trifluoromethyl)vinyl group. Consequently, we accomplished 5-endo-trig $\mathrm{O}$ - and $\mathrm{N}$ cyclizations of intermediary metal enolates and enamides bearing 2-(trifluoromethyl)allylic groups, which led to the synthesis of exo-difluoromethylene-bearing tetrahydrofurans 3 and pyrrolidines 4 , respectively (Scheme $1 \mathrm{~b}$ ).

(a) Previous work

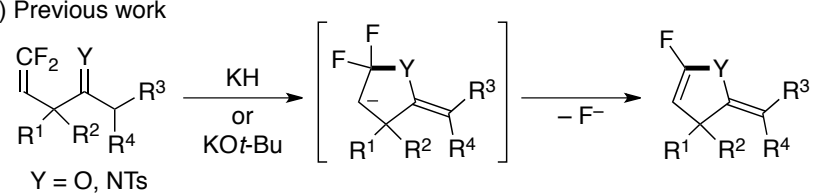

(b) This work

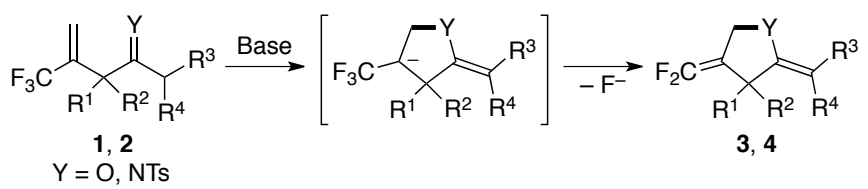

Scheme 1. Nucleophilic 5-endo-trig cyclization of ketones and imines bearing fluoroalkene units

\section{Results and discussion}

\subsection{Preparation of 2-(trifluoromethyl)allylic ketones and imines}



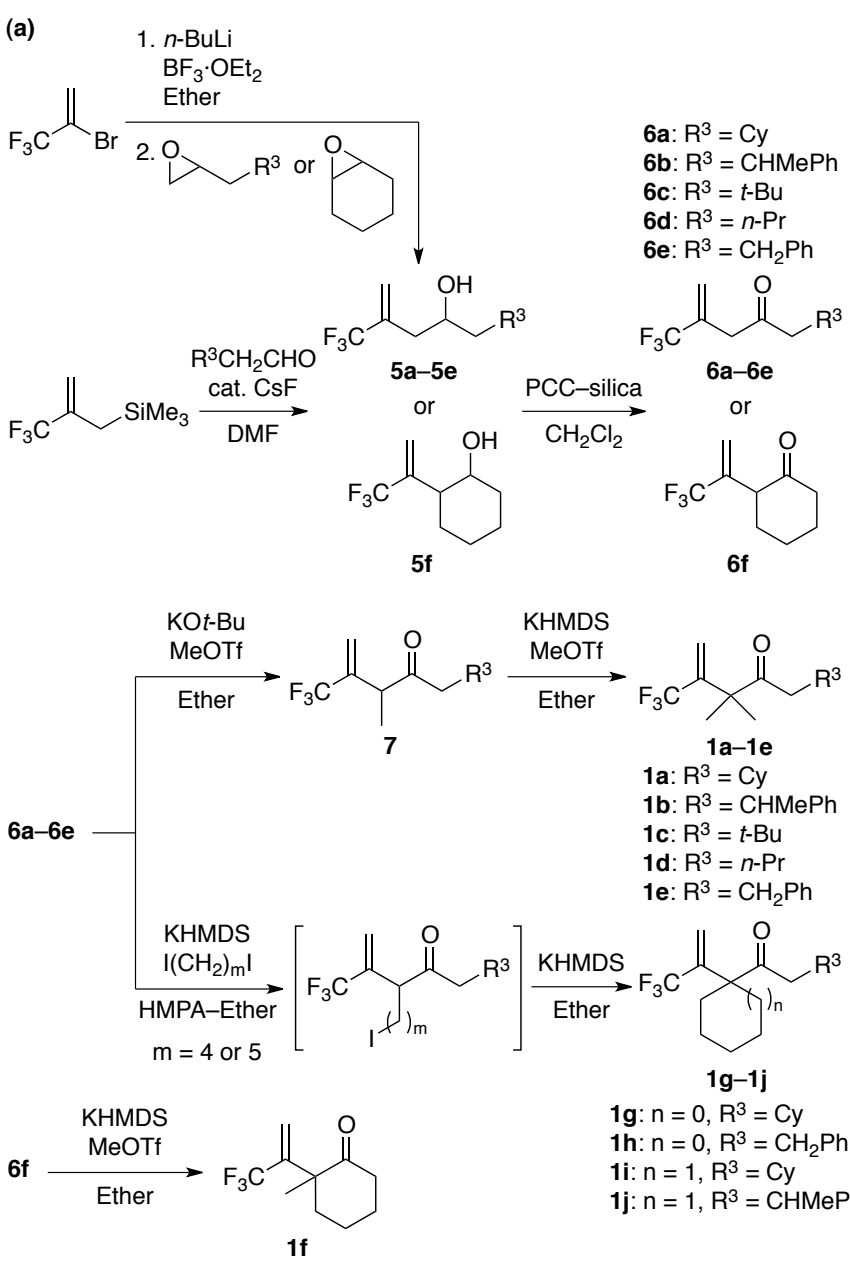

1g: $\mathrm{n}=0, \mathrm{R}^{3}=\mathrm{Cy}$ 1h: $\mathrm{n}=0, \mathrm{R}^{3}=\mathrm{CH}_{2} \mathrm{Ph}$

1i: $n=1, R^{3}=C y$ $1 \mathrm{j}: \mathrm{n}=1, \mathrm{R}^{3}=\mathrm{CHMePh}$

(b)

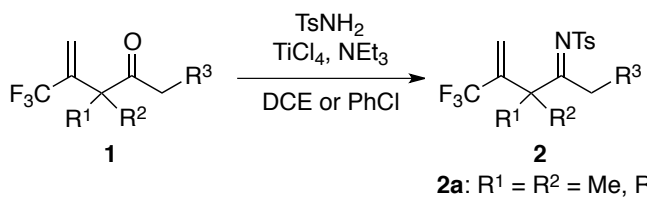

2a: $R^{1}=R^{2}=M e, R^{3}=C y$
2d: $R^{1}=R^{2}=M e, R^{3}=n-P r$

2e: $\mathrm{R}^{1}=\mathrm{R}^{2}=\mathrm{Me}, \mathrm{R}^{3}=\mathrm{CH}_{2} \mathrm{Ph}$

2f: $R^{1}=\mathrm{Me}, \mathrm{R}^{2}, \mathrm{R}^{3}=-\left(\mathrm{CH}_{2}\right)_{3}-$

2h: $R^{1}, R^{2}=-\left(\mathrm{CH}_{2}\right)_{4}-, \mathrm{R}^{3}=\mathrm{CH}_{2} \mathrm{Ph}$

Scheme 2. Preparation of (a) 2-(trifluoromethyl)allylic ketones 1 and (b) 2-(trifluoromethyl)allylic imines $\mathbf{2}$

2-(Trifluoromethyl)allylic ketones 1 were obtained through the preparation of (trifluoromethyl)homoallylic alcohols 5: (i) ring-opening of epoxides with (trifluoromethyl)vinyllithium ${ }^{14}$ or (ii) allylation of aldehydes with trimethyl[(trifluoromethyl)allyl]silane (Scheme 2a) ${ }^{8,15}$ Alcohols 5 were oxidized with pyridinium chlorochromate (PCC) on silica gel to afford the corresponding ketones 6. Subsequent stepwise dimethylation by methyl trifluoromethanesulfonate and appropriate bases afforded 2-(trifluoromethyl)allylic ketones 1a1e bearing two methyl groups. 2-(Trifluoromethyl)allylic ketones $\mathbf{1 g}-\mathbf{1 j}$ with a cycloalkane moiety were prepared via stepwise dialkylation using diiodoalkanes. 2-(Trifluoromethyl)allylic ketone 1f bearing a cyclohexanone framework is also obtained via methylation of 2-(3,3,3-trifluoroprop-1-en-2-yl)cyclohexan1-one (6f, Scheme 2a). Additionally, on treatment with $p$ toluenesulfonamide in the presence of $\mathrm{TiCl}_{4}$ and triethylamine, ketones 1 afforded 2-(trifluoromethyl)allylic imines 2 (Scheme $2 b)$. Imination of $\mathbf{1 f}$ afforded a mixture of imine $\mathbf{2 f}$ and its enamine form (not shown), which was used for the following 5endo-trig cyclization as it is.

\subsection{Cyclization of 2-(trifluoromethyl)allylic ketones}

We initially sought suitable conditions for 5-endo-trig cyclization of 2-(trifluoromethyl)allylic ketones 1 using ketone 1a as a model compound (Table 1). When potassium hydride, lithium diisopropylamide (LDA), lithium hexamethyldisilazide (LiHMDS), and sodium hexamethyldisilazide (NaHMDS) were employed as bases in tetrahydrofuran (THF), cyclized products were hardly obtained (Table 1, Entries 1-4). In contrast, on treatment with potassium hexamethyldisilazide (KHMDS) in THF, $O$-cyclization proceeded exclusively in a 5-endo-trig fashion to afford tetrahydrofuran 3a bearing two alkylidene units in $56 \%$ yield (Table 1, Entry 5). To improve the yield of $\mathbf{3 a}$, several other solvents such as diglyme, toluene, and $N, N$ dimethylformamide (DMF) were examined (Table 1, Entries 69). Among these, DMF was found to be the most effective, affording 3a in $83 \%$ yield (Table 1, Entry 9). Other bases were much less effective even in DMF than KHMDS (Table 1, Entries 10-15).

Table 1. Screening of conditions for 5-endo-trig cyclization of 1a

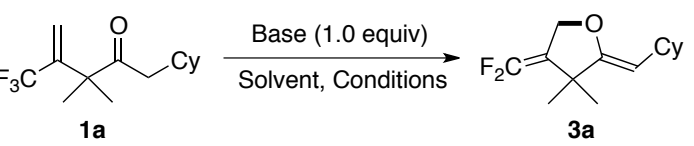

\begin{tabular}{|c|c|c|c|c|}
\hline Entry & Base & Solvent & Conditions & Yield $\%^{a}$ \\
\hline 1 & $\mathrm{KH}$ & THF & reflux, $2 \mathrm{~h}$ & N.D. ${ }^{b}$ \\
\hline 2 & LDA & THF & reflux, $2 \mathrm{~h}$ & N.D. ${ }^{b}$ \\
\hline 3 & LiHMDS & THF & reflux, $4 \mathrm{~h}$ & N.D. ${ }^{b}$ \\
\hline 4 & NaHMDS & THF & reflux, $4 \mathrm{~h}$ & 2 \\
\hline 5 & KHMDS & THF & reflux, $4 \mathrm{~h}$ & 56 \\
\hline 6 & KHMDS & 1,4-Dioxane & reflux, $8 \mathrm{~h}$ & 76 \\
\hline 7 & KHMDS & Diglyme & reflux, $4 \mathrm{~h}$ & 39 \\
\hline 8 & KHMDS & Toluene & reflux, $2 \mathrm{~h}$ & 20 \\
\hline 9 & KHMDS & DMF & $110^{\circ} \mathrm{C}, 1 \mathrm{~h}$ & 83 \\
\hline 10 & $\mathrm{KH}$ & DMF & $110^{\circ} \mathrm{C}, 2 \mathrm{~h}$ & 17 \\
\hline 11 & $\mathrm{NaH}$ & DMF & $110^{\circ} \mathrm{C}, 2 \mathrm{~h}$ & N.D. ${ }^{b}$ \\
\hline 12 & $\mathrm{KO} t-\mathrm{Bu}$ & DMF & $110^{\circ} \mathrm{C}, 2 \mathrm{~h}$ & N.D. ${ }^{b}$ \\
\hline 13 & LDA & DMF & $110^{\circ} \mathrm{C}, 2 \mathrm{~h}$ & N.D. ${ }^{b}$ \\
\hline 14 & LiHMDS & DMF & $110^{\circ} \mathrm{C}, 2 \mathrm{~h}$ & N.D. ${ }^{b}$ \\
\hline 15 & NaHMDS & DMF & $110^{\circ} \mathrm{C}, 2 \mathrm{~h}$ & N.D. ${ }^{b}$ \\
\hline
\end{tabular}

${ }^{\mathrm{a}}$ Yield was determined by ${ }^{19} \mathrm{~F}$ NMR measurement using $\mathrm{PhCF}_{3}$ as an internal standard. ${ }^{\text {DN.D. }}=$ Not detected.

To determine the configuration of the cyclohexylmethylidene unit of tetrahydrofuran $\mathbf{3 a}$, which was obtained as a single isomer, nuclear Overhauser effect (NOE) experiments were conducted. A significant correlation was observed between the vinylic proton $\left(\mathrm{H}^{\mathrm{a}}\right.$ in Figure 1) and the protons of the two methyl groups on the tetrahydrofuran ring, while no NOE correlation was detected between the allylic proton $\left(\mathrm{H}^{\mathrm{b}}\right.$ in Figure 1) and the methyl protons. Therefore, the stereochemistry of $\mathbf{3 a}$ was determined to be $Z$. This might be due to steric repulsion between the methyl groups and the cyclohexane ring, which induces selective formation of $Z$-enolates and subsequent cyclization with retention of configuration. This selectivity is the same as for 5-endo-trig 
cyclization of 3,3-difluoroallylic ketones, which solely produces dihydrofurans bearing $Z$-alkylidene units. ${ }^{13}$

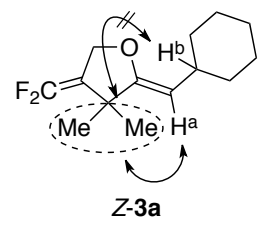

Figure 1. Determination of stereochemistry of 3a by NOE experiments

With the optimal conditions established, the scope and limitations of the 5-endo-trig cyclization of (trifluoromethyl)allylic ketones 1 were investigated (Table 2). Although 3a partially decomposed upon silica gel column chromatography, 3a was isolated in 53\% yield (Table 2, Entry 1). In general, cyclization of substrates bearing a tertiary or quaternary carbon atom at the $\beta$-position of the carbonyl group proceeded efficiently. Dimethylated substrates $\mathbf{1 b}$ and $\mathbf{1 c}$ bearing 1-phehylethyl and tert-butyl groups at the carbon $\alpha$ to the carbonyl group underwent 5-endo-trig cyclization to afford the corresponding tetrahydrofurans $\mathbf{3 b}$ and $\mathbf{3 c}$ in $29 \%$ and $61 \%$ isolated yields, respectively (Table 2, Entries 2 and 3), whereas much lower efficiency was observed in cyclization of phenethyl ketone 1e (not shown). Ketones $\mathbf{1 g}$ and $\mathbf{1 i}-\mathbf{1 j}$ bearing a cyclopentane or a cyclohexane ring at the allylic position were also applicable to 5-endo-trig cyclization, affording spirocyclic products $\mathbf{3 g}, \mathbf{3 i}$, and $\mathbf{3 j}$ bearing a tertiary carbon atom at the outside allylic position in good to high isolated yields (Table 2, Entries 4-6). Cyclohexane-bearing substrate 1i underwent cyclization more efficiently than cyclopentane-bearing substrate 1g, presumably because a cyclohexane ring is more sterically demanding than a cyclopentane ring, and thus rather promoted cyclization by bringing the oxygen atom closer to the alkene moiety (Table 2, Entry 4 vs Entry 5).

Table 2. Synthesis of tetrahydrofurans 3 bearing an exodifluoromethylene unit

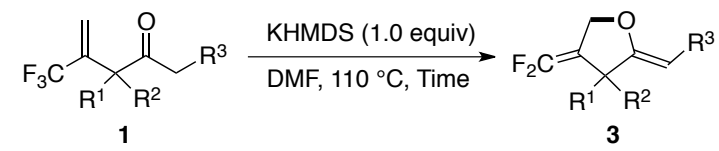

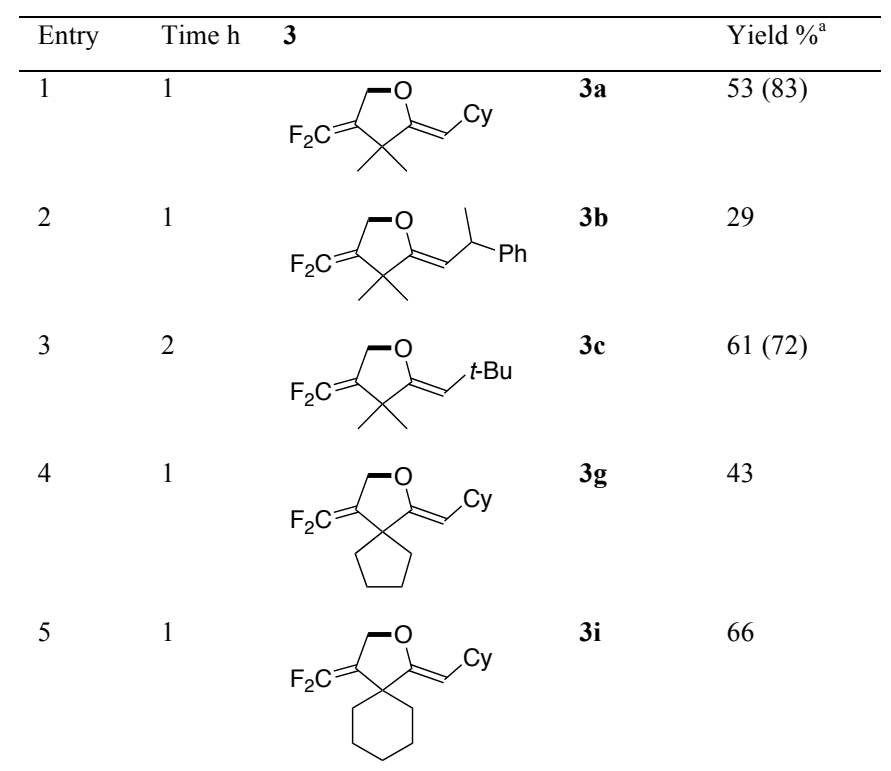

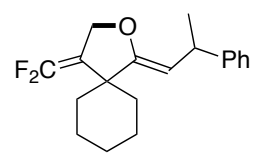

$3 \mathbf{j}$

71

${ }^{\mathrm{a}}$ Isolated yield. Yield determined by ${ }^{19} \mathrm{~F}$ NMR measurement using $\mathrm{PhCF}_{3}$ as an internal standard is shown in parentheses.

\subsection{Cyclization of 2-(trifluoromethyl)allylic imines}

We next examined 5-endo-trig cyclization of 2(trifluoromethyl)allylic imines $\mathbf{2}$ using imine $\mathbf{2 e}$ as a model compound (Table 3). Although no cyclization occurred when treating 2e with potassium hydride in THF (Table 3, Entry 1), using DMF as a solvent afforded the corresponding pyrrolidine 4e in $77 \%$ yield as an $E / Z$ mixture (Table 3, Entry 2). Several other bases were then examined in DMF (Table 3, Entries 3-5). Among these bases, LDA and KHMDS exhibited greater efficiency at $110{ }^{\circ} \mathrm{C}$ to afford $4 \mathrm{e}$ in $86 \%$ and $93 \%$ yields with $23 / 77$ and 26/74 E/Z ratios, respectively (Table 3, Entries 5 and $6)$.

Table 3. Screening of conditions for 5-endo-trig cyclization of $2 \mathbf{e}$

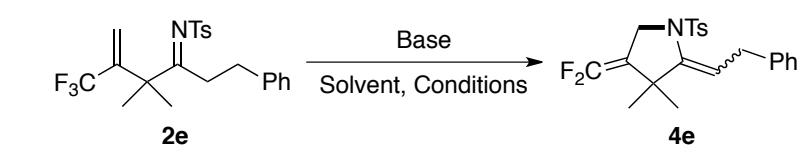

\begin{tabular}{lllll}
\hline Entry & Base (equiv) & Solvent & Conditions & ${\text { Yield } \%(E / Z)^{\mathrm{a}}}^{\circ}$ \\
\hline 1 & $\mathrm{KH}(2.0)$ & $\mathrm{THF}$ & reflux, $8 \mathrm{~h}$ & N.D. ${ }^{\mathrm{b}}$ \\
2 & $\mathrm{KH}(1.0)$ & $\mathrm{DMF}$ & $110^{\circ} \mathrm{C}, 2 \mathrm{~h}$ & $77(23 / 77)$ \\
3 & $\mathrm{NaH} \mathrm{(1.0)}$ & $\mathrm{DMF}$ & $110^{\circ} \mathrm{C}, 5 \mathrm{~h}$ & $81(23 / 77)$ \\
4 & $\mathrm{KOt}-\mathrm{Bu}(2.0)$ & $\mathrm{DMF}$ & $110^{\circ} \mathrm{C}, 2 \mathrm{~h}$ & $65(15 / 85)$ \\
5 & $\mathrm{LDA}(1.0)$ & $\mathrm{DMF}$ & $110^{\circ} \mathrm{C}, 5 \mathrm{~h}$ & $86(23 / 77)$ \\
6 & $\mathrm{KHMDS}(1.0)$ & $\mathrm{DMF}$ & $110^{\circ} \mathrm{C}, 2 \mathrm{~h}$ & $93(26 / 74)$ \\
\hline
\end{tabular}

${ }^{\mathrm{a}}$ Yield was determined by ${ }^{19} \mathrm{~F}$ NMR measurement using $\mathrm{PhCF}_{3}$ as an internal standard. ${ }^{b}$ N.D. $=$ Not detected.

The stereochemistry of pyrrolidine $\mathbf{4 e}$, which was obtained as an $E / Z$ mixture, was determined by NOE experiments as with tetrahydrofuran 3a. The major isomer exhibited correlation between the vinylic proton $\left(\mathrm{H}^{\mathrm{a}}\right.$ in Figure 2$)$ and the protons of the two methyl groups on the pyrrolidine ring, whereas the minor product exhibited correlation between the allylic proton $\left(\mathrm{H}^{\mathrm{b}}\right.$ in Figure 2) and the methyl protons. These observations suggested that the major and minor products were $Z$ - and $E$-isomers of $4 \mathbf{e}$, respectively. This is in stark contrast to the 5-endo-trig cyclization of 3,3-difluoroallylic imines, which afforded $E$ alkylidene dihydropyrroles as major products $(E / Z=>99 /<1-$ 79/21). ${ }^{13 \mathrm{~b}}$ With 3,3-difluoroallylic imines, $Z$-enamides were initially formed, which caused the tosyl group on the nitrogen atom to face the difluoroalkene unit due to steric repulsion and retarded the cyclization. Thus, $E$-enamides, formed by stereoinversion, underwent cyclization. However, in the current reaction, cyclization proceeded from initially formed $Z$-enamides, probably because of the high reactivity of the (trifluoromethyl)alkene unit. 

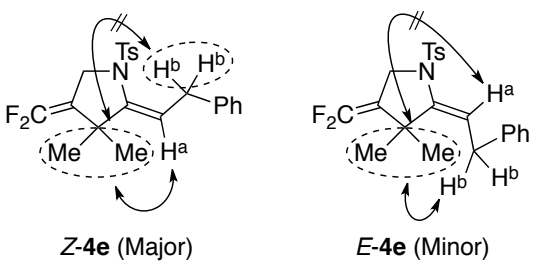

Figure 2. Determination of stereochemistry of $4 \mathbf{e}$ by NOE experiments

Cyclization of several 2-(trifluoromethyl)allylic imines 2 was then investigated using LDA as a base, because it provided satisfying efficiency at lower cost than KHMDS (Table 4). Imines 2a, 2d, and 2e bearing secondary and primary alkyl groups successfully underwent $N$-selective 5-endo-trig cyclization to afford the corresponding pyrrolidines $\mathbf{4 a}, \mathbf{4 d}$, and 4e in $71 \%, 84 \%$, and $76 \%$ yields, respectively (Table 4 , Entries $1-3)$. Cyclization of a mixture of imine $\mathbf{2} \mathbf{f}$ and its enamine form efficiently proceeded to afford indole derivative $4 \mathbf{f}$ in $93 \%$ yield as a sole product (Table 4, Entry 4). Nitrogen-containing spirocyclic compound $\mathbf{4 h}$ was obtained in $85 \%$ yield from imine 2h bearing a cyclopentane moiety at the allylic position (Table 4 , Entry 5).

Table 4. Synthesis of pyrrolidines 4 bearing an exodifluoromethylene unit

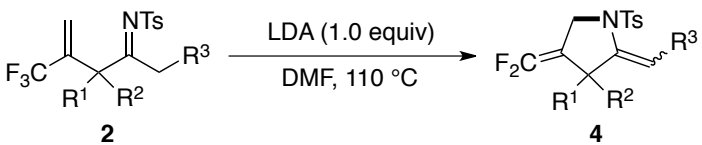

\begin{tabular}{|c|c|c|c|c|}
\hline Entry & Time $\mathrm{h}$ & 4 & & Yield $\%{ }^{\mathrm{a}}(E / Z)^{\mathrm{b}}$ \\
\hline 1 & 2 & & $4 a$ & $71(32 / 68)$ \\
\hline 2 & 2 & & 4d & $84(23 / 77)$ \\
\hline 3 & 5 & & $4 e$ & $76(24 / 76)$ \\
\hline 4 & 2 & & $4 f$ & 93 (N.A.) $^{\mathrm{c}}$ \\
\hline 5 & 2 & & $4 \mathrm{~h}$ & $85(18 / 82)$ \\
\hline
\end{tabular}

${ }^{a}$ Isolated yield. ${ }^{b}$ Diastereomer ratio was determined by ${ }^{19} \mathrm{~F}$ NMR measurement. ${ }^{\mathrm{c} N}$.A. $=$ Not applicable.

\section{Conclusion}

In summary, we have demonstrated nucleophilic 5-endo-trig cyclization of 2-(trifluoromethyl)allylic ketones and imines via their metal enolates and enamides. In both cases, carbonheteroatom bonds were formed during cyclization to afford fivemembered heterocycles with two exo-alkylidene units including a gem-difluoromethylene group. It is noteworthy that single $\mathrm{C}-\mathrm{F}$ bond activation of the trifluoromethyl group was successfully effected to install two fluorine atoms in the products. The fluorine-containing tetrahydrofurans and pyrrolidines thus obtained would serve as constituents of bioactive pharmaceuticals and agrochemicals. ${ }^{1}$

\section{Experimental section}

\subsection{General information}

The ${ }^{1} \mathrm{H}$ NMR, ${ }^{13} \mathrm{C}$ NMR, and ${ }^{19} \mathrm{~F}$ NMR spectra were recorded on a Bruker Avance 500, a JEOL ECS-400, a JEOL ECZ-400S, or a JEOL EX-270 spectrometer. Chemical shift values are given in ppm relative to internal $\mathrm{Me}_{4} \mathrm{Si}$ (for ${ }^{1} \mathrm{H}$ NMR: $\delta=0.00 \mathrm{ppm}$ ), $\mathrm{CDCl}_{3}$ (for ${ }^{13} \mathrm{C}$ NMR: $\delta=77.0 \mathrm{ppm}$ ), and $\mathrm{C}_{6} \mathrm{~F}_{6}$ (for ${ }^{19} \mathrm{~F}$ NMR: $\delta=$ $0.00 \mathrm{ppm})$. IR spectra were recorded on a Horiba FT-300S spectrometer by the attenuated total reflectance (ATR) method. Mass spectra were measured on a JEOL JMS-T100GCV, a JEOL JMS-T100CS, a JEOL JMS-SX-102A, or a Waters UPLC spectrometer. Elemental analyses were performed with a Yanaco MT-3 CHN Coder apparatus at the Elemental Analysis Laboratory, Division of Chemistry, Faculty of Pure and Applied Sciences, University of Tsukuba.

Column chromatography and preparative thin-layer chromatography were conducted on silica gel (Silica Gel $60 \mathrm{~N}$, Kanto Chemical Co., Inc. for column chromatography and Wakogel B-5F, Wako Pure Chemical Industries for PTLC). All the reactions were conducted under argon or nitrogen.

$N, N$-Dimethylformamide (DMF), tetrahydrofuran (THF), and diethyl ether were purified with a solvent-purification system (GlassContour) equipped with columns of activated alumina and supported-copper catalyst (Q-5) before use. $N, N, N^{\prime}, N^{\prime}, N^{\prime \prime}, N^{\prime \prime}$ Hexamethylphosphoric triamide (HMPA) was distilled from $\mathrm{CaH}_{2}$, and stored over activated molecular sieves 4A. Preparation of 1-phenyl-5-(trifluoromethyl)hex-5-en-3-one (6e) and 4,4dimethyl-1-phenyl-5-(trifluoromethyl)hex-5-en-3-one (1e) was conducted according to literature procedures. ${ }^{8 \mathrm{~b}}$ Unless otherwise noted, materials were obtained from commercial sources and used directly without further purification.

\subsection{1-Cyclohexyl-4-(trifluoromethyl)pent-4-en-2-ol (5a)}

To a diethyl ether $(106 \mathrm{~mL})$ solution of 2-bromo-3,3,3trifluoroprop-1-ene $(5.00 \mathrm{~mL}, 48.0 \mathrm{mmol})$ and $\mathrm{BF}_{3} \cdot \mathrm{OEt}_{2}(4.00$ $\mathrm{mL}, 31.9 \mathrm{mmol})$ was added dropwise a diethyl ether $(21 \mathrm{~mL})$ solution of $n$-BuLi (1.47 M in hexane, $32.6 \mathrm{~mL}, 47.9 \mathrm{mmol})$ at $-100{ }^{\circ} \mathrm{C}$. After stirring at $-100{ }^{\circ} \mathrm{C}$ for $15 \mathrm{~min}$, a diethyl ether $(21$ $\mathrm{mL}$ ) solution of 2-(cyclohexylmethyl)oxirane (4.48 g, 31.9 mmol) was added dropwise to the mixture. After stirring at $-100{ }^{\circ} \mathrm{C}$ for $15 \mathrm{~min}$, the mixture was warmed to room temperature. After stirring at room temperature for another $12 \mathrm{~h}$, the reaction was quenched with phosphate buffer ( $\mathrm{pH} 7)$. The organic materials were extracted with ethyl acetate three times. The combined organic extracts were washed with brine and dried over $\mathrm{Na}_{2} \mathrm{SO}_{4}$. After the solvent was removed under reduced pressure, the residue was purified by column chromatography (hexane/ethyl acetate $=5 / 1)$ to give 5a $(4.42 \mathrm{~g}, 59 \%$ ) as a colorless oil; [Found: $\mathrm{C}, 61.07 ; \mathrm{H}, 8.21 . \mathrm{C}_{12} \mathrm{H}_{19} \mathrm{~F}_{3} \mathrm{O}$ requires $\mathrm{C}$, 61.00; H, 8.11\%]; IR (neat) v 3375, 2924, 2854, 1448, 1348, 1167, 1122, 1032, $945 \mathrm{~cm}^{-1} ;{ }^{1} \mathrm{H}$ NMR $\left(500 \mathrm{MHz}, \mathrm{CDC}_{3}\right) \delta$ 0.83-0.92 (m, 1H), 0.92-1.01 (m, 1H), 1.10-1.22 (m, 1H), 1.221.35 (m, 3H), 1.36-1.55 (m, 3H), 1.64-1.74 (m, 4H), 1.77-1.84 (m, 1H), 2.29 (dd, $J=14.9,8.4 \mathrm{~Hz}, 1 \mathrm{H}), 2.39(\mathrm{dd}, J=14.9,3.8$ $\mathrm{Hz}, 1 \mathrm{H}), 3.90-3.97(\mathrm{~m}, 1 \mathrm{H}), 5.48\left(\mathrm{q}, J_{\mathrm{HF}}=1.2 \mathrm{~Hz}, 1 \mathrm{H}\right), 5.80(\mathrm{q}$, $\left.J_{\mathrm{HF}}=1.4 \mathrm{~Hz}, 1 \mathrm{H}\right) ;{ }^{13} \mathrm{C} \mathrm{NMR}\left(126 \mathrm{MHz}, \mathrm{CDCl}_{3}\right) \delta 26.1,26.3$, $26.5,32.7,34.0,34.1,38.7,45.0,66.6,120.9\left(\mathrm{q}, J_{\mathrm{CF}}=6 \mathrm{~Hz}\right)$, $123.6\left(\mathrm{q}, J_{\mathrm{CF}}=274 \mathrm{~Hz}\right), 135.2\left(\mathrm{q}, J_{\mathrm{CF}}=30 \mathrm{~Hz}\right) ;{ }^{19} \mathrm{~F}$ NMR $(470$ $\left.\mathrm{MHz}, \mathrm{CDC1}_{3}\right) \delta 93.5$ (br s, 3F). 


\subsection{6,6-Dimethyl-2-(trifluoromethyl)hept-1-en-4-ol (5c)}

Compound $\mathbf{5 c}$ was prepared by the method described for $\mathbf{5 a}$ using 2-bromo-3,3,3-trifluoroprop-1-ene $(1.10 \mathrm{~mL}, 10.6 \mathrm{mmol})$ and 2-neopentyloxirane $(769 \mathrm{mg}, 6.74 \mathrm{mmol})$. Purification by column chromatography (hexane/ethyl acetate $=5 / 1$ ) gave $\mathbf{5 c}$ $(801 \mathrm{mg}, 57 \%)$ as a colorless oil; [Found: C, 56.88; H, 8.19. $\mathrm{C}_{10} \mathrm{H}_{17} \mathrm{~F}_{3} \mathrm{O}$ requires $\mathrm{C}, 57.13 ; \mathrm{H}, 8.15 \%$ ]; IR (neat) v 3396, 2956, $2871,1365,1346,1165,1117,945,874,580 \mathrm{~cm}^{-1} ;{ }^{1} \mathrm{H}$ NMR $(500$ $\left.\mathrm{MHz}, \mathrm{CDC1}_{3}\right) \delta 0.98(\mathrm{~s}, 9 \mathrm{H}), 1.39-1.42(\mathrm{~m}, 2 \mathrm{H}), 1.52(\mathrm{br} \mathrm{s}, 1 \mathrm{H})$, $2.31(\mathrm{dd}, J=14.8,8.5 \mathrm{~Hz}, 1 \mathrm{H}), 2.36(\mathrm{dd}, J=14.8,4.6 \mathrm{~Hz}, 1 \mathrm{H})$, $3.93-3.99(\mathrm{~m}, 1 \mathrm{H}), 5.47$ (br s, $1 \mathrm{H}), 5.80\left(\mathrm{q}, J_{\mathrm{HF}}=1.2 \mathrm{~Hz}, 1 \mathrm{H}\right)$; ${ }^{13} \mathrm{C}$ NMR $\left(126 \mathrm{MHz}, \mathrm{CDCl}_{3}\right) \delta 30.0,30.3,40.1,50.6,66.9,121.1$ $\left(\mathrm{q}, J_{\mathrm{CF}}=6 \mathrm{~Hz}\right), 123.6\left(\mathrm{q}, J_{\mathrm{CF}}=274 \mathrm{~Hz}\right), 135.2\left(\mathrm{q}, J_{\mathrm{CF}}=29 \mathrm{~Hz}\right)$; ${ }^{19} \mathrm{~F} \mathrm{NMR}\left(470 \mathrm{MHz}, \mathrm{CDCl}_{3}\right) \delta 93.6$ (br s, 3F).

\subsection{2-(3,3,3-Trifluoroprop-1-en-2-yl)cyclohexan-1-ol (5f)}

Compound $\mathbf{5 f}$ was prepared by the method described for $\mathbf{5 a}$ using 2-bromo-3,3,3-trifluoroprop-1-ene (12.4 mL, $119 \mathrm{mmol})$ and 7-oxabicyclo[4.1.0]heptane $(8.01 \mathrm{~g}, 81.6 \mathrm{mmol})$. Purification by column chromatography (hexane/ethyl acetate $=4 / 1$ ) gave $\mathbf{5 f}$ $(8.48 \mathrm{~g}, 54 \%)$ as a colorless oil; IR (neat) $v$ 3404, 2933, 2860, 1450, 1346, 1296, 1163, 1113, 1063, $937 \mathrm{~cm}^{-1}$; ${ }^{1} \mathrm{H}$ NMR $(500$ $\left.\mathrm{MHz}, \mathrm{CDCl}_{3}\right) \delta 1.22-1.34(\mathrm{~m}, 4 \mathrm{H}), 1.69-1.72(\mathrm{~m}, 1 \mathrm{H}), 1.78$ $1.82(\mathrm{~m}, 1 \mathrm{H}), 1.92-1.94(\mathrm{~m}, 1 \mathrm{H}), 2.02(\mathrm{br} \mathrm{s}, 1 \mathrm{H}), 2.07-2.10(\mathrm{~m}$, $1 \mathrm{H}), 2.11-2.16(\mathrm{~m}, 1 \mathrm{H}), 3.57-3.62(\mathrm{~m}, 1 \mathrm{H}), 5.49$ (br s, $1 \mathrm{H}), 5.85$ $\left(\mathrm{q}, J_{\mathrm{HF}}=1.3 \mathrm{~Hz}, 1 \mathrm{H}\right) ;{ }^{13} \mathrm{C} \mathrm{NMR}\left(126 \mathrm{MHz}, \mathrm{CDCl}_{3}\right) \delta 24.7,25.7$, $33.0,34.9,47.1,72.6,118.5\left(\mathrm{q}, J_{\mathrm{CF}}=6 \mathrm{~Hz}\right), 123.8\left(\mathrm{q}, J_{\mathrm{CF}}=274\right.$ $\mathrm{Hz}), 140.8\left(\mathrm{q}, J_{\mathrm{CF}}=29 \mathrm{~Hz}\right) ;{ }^{19} \mathrm{~F}$ NMR $\left(470 \mathrm{MHz}, \mathrm{CDC1}_{3}\right) \delta 94.0$ (br s, 3F); HRMS (FAB): $\mathrm{MH}^{+}$, found 195.0977. $\mathrm{C}_{9} \mathrm{H}_{14} \mathrm{~F}_{3} \mathrm{O}$ requires 195.0997.

\subsection{1-Cyclohexyl-4-(trifluoromethyl)pent-4-en-2-one (6a)}

To a dichloromethane $(45 \mathrm{~mL})$ suspension of pyridinium chlorochromate (4.98 g, $23.1 \mathrm{mmol})$ and silica gel (5.02 g) was added alcohol 5a (3.56 g, $15.1 \mathrm{mmol})$. After stirring at room temperature for $13 \mathrm{~h}$, the mixture was filtered through a pad of Celite (diethyl ether). After the solvent was removed under reduced pressure, the residue was purified by column chromatography (hexane/ethyl acetate $=10 / 1)$ to give $\mathbf{6 a}(3.21 \mathrm{~g}$, 91\%) as a colorless oil; [Found: $\mathrm{C}, 61.35 ; \mathrm{H}, 7.49 . \mathrm{C}_{12} \mathrm{H}_{17} \mathrm{~F}_{3} \mathrm{O}$ requires $\mathrm{C}, 61.53$; $\mathrm{H}, 7.31 \%$ ]; IR (neat) $v 2925,2854,1722,1450$, $1412,1356,1306,1173,1124,949,744 \mathrm{~cm}^{-1} ;{ }^{1} \mathrm{H}$ NMR $(500$ $\left.\mathrm{MHz}, \mathrm{CDCl}_{3}\right) \delta$ 0.87-0.97 (m, 2H), 1.08-1.18 (m, 1H), 1.22 $1.32(\mathrm{~m}, 2 \mathrm{H}), 1.62-1.72(\mathrm{~m}, 5 \mathrm{H}), 1.80-1.89(\mathrm{~m}, 1 \mathrm{H}), 2.36(\mathrm{~d}, J=$ $6.9 \mathrm{~Hz}, 2 \mathrm{H}) .3 .25$ (br s, $2 \mathrm{H}), 5.50\left(\mathrm{q}, J_{\mathrm{HF}}=1.2 \mathrm{~Hz}, 1 \mathrm{H}\right), 5.91(\mathrm{q}$, $\left.J_{\mathrm{HF}}=1.5 \mathrm{~Hz}, 1 \mathrm{H}\right) ;{ }^{13} \mathrm{C} \mathrm{NMR}\left(126 \mathrm{MHz}, \mathrm{CDCl}_{3}\right) \delta 26.0,26.3$, $33.0,33.6,43.5,50.2,122.6\left(\mathrm{q}, J_{\mathrm{CF}}=6 \mathrm{~Hz}\right), 123.1\left(\mathrm{q}, J_{\mathrm{CF}}=274\right.$ $\mathrm{Hz}), 131.4$ (q, $\left.J_{\mathrm{CF}}=31 \mathrm{~Hz}\right), 204.9 ;{ }^{19} \mathrm{~F}$ NMR $\left(470 \mathrm{MHz}, \mathrm{CDC1}_{3}\right)$ $\delta 92.7$ (br s, 3F).

\subsection{6,6-Dimethyl-2-(trifluoromethyl)hept-1-en-4-one (6c)}

Compound $\mathbf{6 c}$ was prepared by the method described for $\mathbf{6 a}$ using alcohol 5c $(740 \mathrm{mg}, 3.52 \mathrm{mmol})$. Purification by column chromatography (hexane/ethyl acetate $=5 / 1)$ gave 6c $(564 \mathrm{mg}$, $77 \%$ ) as a colorless oil; [Found: $\mathrm{C}, 57.60 ; \mathrm{H}, 7.42 . \mathrm{C}_{10} \mathrm{H}_{15} \mathrm{~F}_{3} \mathrm{O}$ requires $\mathrm{C}, 57.68 ; \mathrm{H}, 7.26 \%$ ]; IR (neat) $v 2958,2871,1662,1468$, $1414,1356,1300,1171,1119,949,598 \mathrm{~cm}^{-1}$; ${ }^{1} \mathrm{H}$ NMR $(500$ $\left.\mathrm{MHz}, \mathrm{CDC1}_{3}\right) \delta 1.03$ (s, 9H), 2.39 (s, 2H), 3.26 (s, 2H), 5.48 (q, $\left.J_{\mathrm{HF}}=1.1 \mathrm{~Hz}, 1 \mathrm{H}\right), 5.91\left(\mathrm{q}, J_{\mathrm{HF}}=1.5 \mathrm{~Hz}, 1 \mathrm{H}\right) ;{ }^{13} \mathrm{C}$ NMR $(126$ $\left.\mathrm{MHz}, \mathrm{CDCl}_{3}\right) \delta 29.5,31.0,44.9,54.6,122.7$ (q, $\left.J_{\mathrm{CF}}=6 \mathrm{~Hz}\right)$, $123.1\left(\mathrm{q}, J_{\mathrm{CF}}=274 \mathrm{~Hz}\right), 131.4\left(\mathrm{q}, J_{\mathrm{CF}}=31 \mathrm{~Hz}\right), 204.7 ;{ }^{19} \mathrm{~F}$ NMR $\left(470 \mathrm{MHz}, \mathrm{CDC1}_{3}\right) \delta 92.7$ (br s, 3F).

\subsection{2-(3,3,3-Trifluoroprop-1-en-2-yl)cyclohexan-1-one (6f)}

Compound $\mathbf{6 f}$ was prepared by the method described for $\mathbf{6 a}$ using alcohol $\mathbf{5 f}(1.21 \mathrm{~g}, 6.22 \mathrm{mmol})$. Purification by column chromatography (hexane/ethyl acetate $=5 / 1)$ gave 6 f $(978 \mathrm{mg}$, $82 \%$ ) as a colorless oil; IR (neat) $v 2939,2870,1720,1334,1297$, 1240, 1171, 1120, $945 \mathrm{~cm}^{-1}$; ${ }^{1} \mathrm{H}$ NMR $\left(500 \mathrm{MHz}, \mathrm{CDC1}_{3}\right) \delta$ $1.69-1.84(\mathrm{~m}, 3 \mathrm{H}), 1.93-2.03(\mathrm{~m}, 1 \mathrm{H}), 2.12-2.19(\mathrm{~m}, 1 \mathrm{H}), 2.20$ $2.27(\mathrm{~m}, 1 \mathrm{H}), 2.38-2.46(\mathrm{~m}, 1 \mathrm{H}), 2.48-2.54(\mathrm{~m}, 1 \mathrm{H}), 3.28(\mathrm{dd}, J$ $=12.0,5.0, \mathrm{~Hz}, 1 \mathrm{H}), 5.44($ br s, $1 \mathrm{H}), 5.98\left(\mathrm{q}, J_{\mathrm{HF}}=1.5 \mathrm{~Hz}, 1 \mathrm{H}\right)$; ${ }^{13} \mathrm{C}$ NMR $\left(126 \mathrm{MHz}, \mathrm{CDCl}_{3}\right) \delta 25.4,27.9,34.3,42.2,51.1,121.2$ $\left(\mathrm{q}, J_{\mathrm{CF}}=6 \mathrm{~Hz}\right), 123.4\left(\mathrm{q}, J_{\mathrm{CF}}=274 \mathrm{~Hz}\right), 135.9\left(\mathrm{q}, J_{\mathrm{CF}}=30 \mathrm{~Hz}\right)$, 207.1; ${ }^{19} \mathrm{~F}$ NMR $\left(470 \mathrm{MHz}, \mathrm{CDCl}_{3}\right) \delta 93.5$ (br s, 3F); HRMS (EI): $\mathrm{MH}^{+}$, found 192.0767. $\mathrm{C}_{9} \mathrm{H}_{11} \mathrm{~F}_{3} \mathrm{O}$ requires 192.0762 .

\subsection{1-Cyclohexyl-3-methyl-4-(trifluoromethyl)pent-4-en-2-one (7a)}

To a diethyl ether $(60 \mathrm{~mL})$ solution of ketone $\mathbf{6 a}(2.83 \mathrm{~g}, 12.1$ mmol) was added potassium tert-butoxide $(1.54 \mathrm{~g}, 13.7 \mathrm{mmol})$ at $-78{ }^{\circ} \mathrm{C}$. After stirring at $-78{ }^{\circ} \mathrm{C}$ for $1 \mathrm{~h}$, methyl trifluoromethanesulfonate $(2.00 \mathrm{~mL}, 17.7 \mathrm{mmol})$ was added to the mixture. After stirring at $-78{ }^{\circ} \mathrm{C}$ for $20 \mathrm{~min}$, the mixture was warmed to room temperature and stirred for another $11 \mathrm{~h}$. The reaction was quenched with phosphate buffer $(\mathrm{pH} 7)$. The organic materials were extracted with ethyl acetate three times. The combined organic extracts were washed with brine and dried over $\mathrm{Na}_{2} \mathrm{SO}_{4}$. After the solvent was removed under reduced pressure, the residue was purified by column chromatography (hexane/ethyl acetate $=10 / 1)$ to give $7 \mathbf{a}(2.83 \mathrm{~g}, 95 \%)$ as a colorless oil; [Found: $\mathrm{C}, 62.92 ; \mathrm{H}, 7.94 . \mathrm{C}_{13} \mathrm{H}_{19} \mathrm{~F}_{3} \mathrm{O}$ requires $\mathrm{C}$, 62.89; H, 7.71\%]; IR (neat) v 2927, 2854, 1720, 1450, 1306, 1284, 1174, 1124, $951 \mathrm{~cm}^{-1}$; ${ }^{1} \mathrm{H}$ NMR $\left(500 \mathrm{MHz}, \mathrm{CDC1}_{3}\right) \delta$ 0.82-0.96 (m, 2H), 1.07-1.17 (m, 1H), 1.21-1.32 (m, 2H), 1.27 $(\mathrm{d}, J=7.1 \mathrm{~Hz}, 3 \mathrm{H}), 1.60-1.71(\mathrm{~m}, 5 \mathrm{H}), 1.79-1.88(\mathrm{~m}, 1 \mathrm{H}), 2.30$ $2.39(\mathrm{~m}, 2 \mathrm{H}), 3.39$ (q, $J=7.1 \mathrm{~Hz}, 1 \mathrm{H}), 5.46(\mathrm{br} \mathrm{s}, 1 \mathrm{H}), 5.89$ (q, $\left.J_{\mathrm{HF}}=1.3 \mathrm{~Hz}, 1 \mathrm{H}\right) ;{ }^{13} \mathrm{C}$ NMR $\left(126 \mathrm{MHz}, \mathrm{CDCl}_{3}\right) \delta 16.8,26.00$, $26.05,26.2,32.9,33.1,33.3,45.8,48.9,120.2\left(\mathrm{q}, J_{\mathrm{CF}}=6 \mathrm{~Hz}\right)$, $123.4\left(\mathrm{q}, J_{\mathrm{CF}}=274 \mathrm{~Hz}\right), 137.7\left(\mathrm{q}, J_{\mathrm{CF}}=30 \mathrm{~Hz}\right), 208.0 ;{ }^{19} \mathrm{~F} \mathrm{NMR}$ $\left(470 \mathrm{MHz}, \mathrm{CDCl}_{3}\right) \delta 93.2$ (br s, 3F).

\subsection{3,6,6-Trimethyl-2-(trifluoromethyl)hept-1-en-4-one (7c)}

Compound 7c was prepared by the method described for $7 \mathbf{a}$ using ketone 6c $(1.36 \mathrm{~g}, 6.53 \mathrm{mmol})$ and methyl trifluoromethanesulfonate $(1.10 \mathrm{~mL}, 9.72 \mathrm{mmol})$. Purification by column chromatography (pentane/ethyl acetate $=20 / 1$ ) gave 7 c $(1.25 \mathrm{~g}, 86 \%)$ as a colorless oil; [Found: C, 59.38; H, 7.72. $\mathrm{C}_{11} \mathrm{H}_{17} \mathrm{~F}_{3} \mathrm{O}$ requires $\mathrm{C}, 59.45 ; \mathrm{H}, 7.71 \%$ ]; IR (neat) $v 2956,2871$, $1720,1466,1304,1273,1171,1119,1082,951 \mathrm{~cm}^{-1} ;{ }^{1} \mathrm{H}$ NMR $\left(500 \mathrm{MHz}, \mathrm{CDCl}_{3}\right) \delta 1.01(\mathrm{~s}, 9 \mathrm{H}), 1.26(\mathrm{~d}, J=7.0 \mathrm{~Hz}, 3 \mathrm{H}), 2.35$ $(\mathrm{d}, J=16.1 \mathrm{~Hz}, 1 \mathrm{H}), 2.40(\mathrm{~d}, J=16.1 \mathrm{~Hz}, 1 \mathrm{H}), 3.37(\mathrm{q}, J=7.0$ $\mathrm{Hz}, 1 \mathrm{H}), 5.44\left(\mathrm{q}, J_{\mathrm{HF}}=0.5 \mathrm{~Hz}, 1 \mathrm{H}\right), 5.85\left(\mathrm{q}, J_{\mathrm{HF}}=0.5 \mathrm{~Hz}, 1 \mathrm{H}\right)$; ${ }^{13} \mathrm{C}$ NMR $\left(126 \mathrm{MHz}, \mathrm{CDCl}_{3}\right) \delta 16.7,29.5,30.8,46.6,53.5,120.2$ $\left(\mathrm{q}, J_{\mathrm{CF}}=6 \mathrm{~Hz}\right), 123.4\left(\mathrm{q}, J_{\mathrm{CF}}=274 \mathrm{~Hz}\right), 137.9\left(\mathrm{q}, J_{\mathrm{CF}}=30 \mathrm{~Hz}\right)$, 207.8; ${ }^{19} \mathrm{~F}$ NMR (470 MHz, CDC1 13 ) $\delta 93.1$ (br s, 3F).

\subsection{3-Methyl-2-(trifluoromethyl)oct-1-en-4-one (7d)}

To a diethyl ether $(125 \mathrm{~mL})$ solution of 2-bromo-3,3,3trifluoroprop-1-ene $(7.76 \mathrm{~mL}, 74.1 \mathrm{mmol})$ and $\mathrm{BF}_{3} \cdot \mathrm{OEt}_{2}(6.23$ $\mathrm{mL}, 50.5 \mathrm{mmol})$ was added dropwise a diethyl ether $(50 \mathrm{~mL})$ solution of $n$-BuLi (2.64 M in hexane, $27.2 \mathrm{~mL}, 71.9 \mathrm{mmol}$ ) at $-110^{\circ} \mathrm{C}$. After stirring at $-110^{\circ} \mathrm{C}$ for $15 \mathrm{~min}$, a diethyl ether $(25$ $\mathrm{mL})$ solution of 2-butyloxirane $(5.00 \mathrm{~g}, 49.9 \mathrm{mmol})$ was added dropwise to the mixture. After stirring at $-110{ }^{\circ} \mathrm{C}$ for $15 \mathrm{~min}$, the mixture was warmed to $-60{ }^{\circ} \mathrm{C}$. After stirring at $-60{ }^{\circ} \mathrm{C}$ for another $10 \mathrm{~min}$, the reaction was quenched with phosphate buffer $(\mathrm{pH} 7)$. The organic materials were extracted with diethyl ether three times. The combined organic 
extracts were washed with brine and dried over $\mathrm{Na}_{2} \mathrm{SO}_{4}$. After the solvent was removed under reduced pressure, the residue was purified by column chromatography (heptane/ethyl acetate $=5 / 1$ ) to give a crude mixture $(3.44 \mathrm{~g})$ including 2-(trifluoromethyl)oct1-en-4-ol (5d) as a pale yellow oil.

To a dichloromethane $(30 \mathrm{~mL})$ suspension of pyridinium chlorochromate $(6.07 \mathrm{~g}, 28.2 \mathrm{mmol})$ and silica gel $(6.07 \mathrm{~g})$ was added the obtained crude mixture. After stirring at room temperature for $39 \mathrm{~h}$, the mixture was filtered through a pad of Celite (dichloromethane). After the solvent was removed under reduced pressure, the residue was purified by column chromatography (heptane/ethyl acetate $=4 / 1$ ) to give a crude mixture $(2.19 \mathrm{~g})$ including 2-(trifluoromethyl)oct-1-en-4-one (6d) as a pale yellow oil.

To a diethyl ether $(46 \mathrm{~mL})$ solution of the obtained crude mixture was added potassium tert-butoxide $(1.14 \mathrm{~g}, 10.2 \mathrm{mmol})$ at $-78{ }^{\circ} \mathrm{C}$. After stirring at $-78{ }^{\circ} \mathrm{C}$ for $30 \mathrm{~min}$, methyl trifluoromethanesulfonate $(1.62 \mathrm{~mL}, 14.3 \mathrm{mmol})$ was added to the mixture. After stirring at $-78{ }^{\circ} \mathrm{C}$ for $20 \mathrm{~min}$, the mixture was warmed to room temperature and stirred for another $22 \mathrm{~h}$. The reaction was quenched with phosphate buffer $(\mathrm{pH} 7)$. The organic materials were extracted with diethyl ether three times. The combined organic extracts were washed with brine and dried over $\mathrm{Na}_{2} \mathrm{SO}_{4}$. After the solvent was removed under reduced pressure, the residue was purified by column chromatography (heptane/ethyl acetate $=10 / 1)$ to give $7 \mathbf{d}(1.12 \mathrm{~g}, 11 \%)$ as a yellow oil; IR (neat) v 2962, 2877, 1722, 1458, 1412, 1342, 1304 1173, 1124, 953, $737 \mathrm{~cm}^{-1}$; ${ }^{1} \mathrm{H}$ NMR $\left(500 \mathrm{MHz}, \mathrm{CDC1}_{3}\right) \delta 0.90$ $(\mathrm{t}, J=7.4 \mathrm{~Hz}, 3 \mathrm{H}), 1.24-1.34(\mathrm{~m}, 2 \mathrm{H}), 1.29(\mathrm{~d}, J=7.2 \mathrm{~Hz}, 3 \mathrm{H})$, $1.51-1.60(\mathrm{~m}, 2 \mathrm{H}), 2.40-2.56(\mathrm{~m}, 2 \mathrm{H}), 3.43(\mathrm{q}, J=7.2 \mathrm{~Hz}, 1 \mathrm{H})$, 5.47 (br s, $1 \mathrm{H}), 5.87$ (br s, $1 \mathrm{H}) ;{ }^{13} \mathrm{C}$ NMR $\left(126 \mathrm{MHz} \mathrm{CDCl}_{3}\right) \delta$ $13.7,16.7,22.1,25.7,40.8,45.4,120.1\left(\mathrm{q}, J_{\mathrm{CF}}=6 \mathrm{~Hz}\right), 123.4(\mathrm{q}$, $\left.J_{\mathrm{CF}}=274 \mathrm{~Hz}\right), 137.9\left(\mathrm{q}, J_{\mathrm{CF}}=30 \mathrm{~Hz}\right), 208.6 ;{ }^{19} \mathrm{~F}$ NMR $(470 \mathrm{MHz}$, $\mathrm{CDC1}_{3}$ ) $\delta 93.2$ (br s, 3F); HRMS (EI): $\mathrm{M}^{+}$, found 208.1078. $\mathrm{C}_{10} \mathrm{H}_{15} \mathrm{~F}_{3} \mathrm{O}$ requires 208.1075 .

\subsection{1-Cyclohexyl-3,3-dimethyl-4-(trifluoromethyl)pent-4-en-2- one (1a)}

To a diethyl ether $(37 \mathrm{~mL})$ solution of ketone $7 \mathbf{a}(1.00 \mathrm{~g}, 4.03$ mmol) was added dropwise a toluene solution of potassium hexamethyldisilazide $(0.50 \mathrm{M}, 11.3 \mathrm{~mL}, 5.6 \mathrm{mmol})$ at $-100{ }^{\circ} \mathrm{C}$. After stirring at $-90{ }^{\circ} \mathrm{C}$ for $30 \mathrm{~min}$, methyl trifluoromethanesulfonate $(0.70 \mathrm{~mL}, 6.2 \mathrm{mmol})$ was added to the mixture at $-100{ }^{\circ} \mathrm{C}$. After stirring for $10 \mathrm{~min}$ at $-100{ }^{\circ} \mathrm{C}$, the reaction mixture was warmed to room temperature and stirred for another $16 \mathrm{~h}$. The reaction was quenched with phosphate buffer $(\mathrm{pH} 7)$. The organic materials were extracted with diethyl ether three times. The combined organic extracts were washed with brine and dried over $\mathrm{Na}_{2} \mathrm{SO}_{4}$. After the solvent was removed under reduced pressure, the residue was purified by column chromatography (heptane/ethyl acetate $=5 / 1)$ to give $\mathbf{1 a}(959 \mathrm{mg}$, $91 \%$ ) as a colorless liquid; [Found: $\mathrm{C}, 64.21 ; \mathrm{H}, 7.98 . \mathrm{C}_{14} \mathrm{H}_{21} \mathrm{~F}_{3} \mathrm{O}$ requires $\mathrm{C}, 64.10 ; \mathrm{H}, 8.07 \%$; IR (neat) $v 2924,2852,1716,1450$, 1327, 1178, 1126, 1097, 1038, $949 \mathrm{~cm}^{-1}$; ${ }^{1} \mathrm{H}$ NMR $(500 \mathrm{MHz}$,

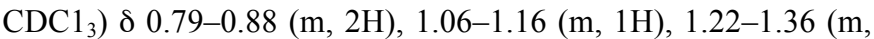
$2 \mathrm{H}), 1.32(\mathrm{~s}, 6 \mathrm{H}), 1.60-1.69(\mathrm{~m}, 5 \mathrm{H}), 1.81-1.90(\mathrm{~m}, 1 \mathrm{H}), 2.26(\mathrm{~d}$, $J=6.7 \mathrm{~Hz}, 2 \mathrm{H}), 5.61\left(\mathrm{q}, J_{\mathrm{HF}}=0.6 \mathrm{~Hz}, 1 \mathrm{H}\right), 5.93\left(\mathrm{q}, J_{\mathrm{HF}}=1.0 \mathrm{~Hz}\right.$, $1 \mathrm{H}) ;{ }^{13} \mathrm{C}$ NMR $\left(126 \mathrm{MHz}, \mathrm{CDCl}_{3}\right) \delta 23.7,26.1,26.2,33.0,33.1$, $44.3,50.5,120.7\left(\mathrm{q}, J_{\mathrm{CF}}=6 \mathrm{~Hz}\right), 123.7\left(\mathrm{q}, J_{\mathrm{CF}}=277 \mathrm{~Hz}\right), 142.7$ $\left(\mathrm{q}, J_{\mathrm{CF}}=28 \mathrm{~Hz}\right), 209.6 ;{ }^{19} \mathrm{~F}$ NMR $\left(470 \mathrm{MHz}, \mathrm{CDC1}_{3}\right) \delta 100.3(\mathrm{br}$ $\mathrm{s}, 3 \mathrm{~F})$.

4.12. 3,3,6,6-Tetramethyl-2-(trifluoromethyl)hept-1-en-4-one (1c)
Compound 1c was prepared by the method described for 1a using ketone 7c $(1.17 \mathrm{~g}, \quad 5.26 \mathrm{mmol})$ and methyl trifluoromethanesulfonate $(0.89 \mathrm{~mL}, 7.9 \mathrm{mmol})$. Purification by column chromatography (pentane/ethyl acetate $=20 / 1$ ) gave $\mathbf{1 c}$ $(1.01 \mathrm{~g}, 81 \%)$ as a colorless liquid; [Found: C, 60.78; H, 7.91. $\mathrm{C}_{12} \mathrm{H}_{19} \mathrm{~F}_{3} \mathrm{O}$ requires $\mathrm{C}, 61.00 ; \mathrm{H}, 8.11 \%$ ]; IR (neat) $v 2956,2871$, $1718,1365,1327,1124,1097,1051,951,910,696 \mathrm{~cm}^{-1} ;{ }^{1} \mathrm{H}$ NMR (500 MHz, $\left.\mathrm{CDCl}_{3}\right) \delta 1.00(\mathrm{~s}, 9 \mathrm{H}), 1.31(\mathrm{~s}, 6 \mathrm{H}), 2.31(\mathrm{~s}$, $2 \mathrm{H}), 5.61$ (br s, $1 \mathrm{H}), 5.92$ (br s, $1 \mathrm{H}) ;{ }^{13} \mathrm{C} \mathrm{NMR} \mathrm{(126} \mathrm{MHz,}$ $\left.\mathrm{CDCl}_{3}\right) \delta 23.8,29.4,30.3,48.3,51.0,120.6\left(\mathrm{q}, J_{\mathrm{CF}}=6 \mathrm{~Hz}\right), 123.7$ $\left(\mathrm{q}, J_{\mathrm{CF}}=277 \mathrm{~Hz}\right), 142.9\left(\mathrm{q}, J_{\mathrm{CF}}=28 \mathrm{~Hz}\right), 209.3 ;{ }^{19} \mathrm{~F}$ NMR $(470$ $\left.\mathrm{MHz}, \mathrm{CDC1}_{3}\right) \delta 100.4$ (br s, 3F).

\subsection{3,3-Dimethyl-2-(trifluoromethyl)oct-1-en-4-one (1d)}

Compound 1d was prepared by the method described for 1a using ketone 7d (895 $\mathrm{mg}, 4.30 \mathrm{mmol})$ and methyl trifluoromethanesulfonate $(0.75 \mathrm{~mL}, 6.6 \mathrm{mmol})$. Purification by column chromatography (heptane/ethyl acetate $=5 / 1$ ) gave $\mathbf{1 d}$ $(618 \mathrm{mg}, 65 \%)$ as a pale yellow oil; IR (neat) $v 2962,2875,1716$, $1466,1410,1327,1178,1130,1101,914,744 \mathrm{~cm}^{-1} ;{ }^{1} \mathrm{H} \mathrm{NMR}$ $\left(500 \mathrm{MHz}, \mathrm{CDCl}_{3}\right) \delta 0.89(\mathrm{t}, J=7.4 \mathrm{~Hz}, 3 \mathrm{H}), 1.24-1.31(\mathrm{~m}, 2 \mathrm{H})$, $1.33(\mathrm{~s}, 6 \mathrm{H}) 1.49-1.56(\mathrm{~m}, 2 \mathrm{H}), 2.40(\mathrm{t}, J=7.4 \mathrm{~Hz}, 2 \mathrm{H}), 5.62(\mathrm{br}$ $\mathrm{s}, 1 \mathrm{H}), 5.94$ (br s, $1 \mathrm{H}) ;{ }^{13} \mathrm{C}$ NMR $\left(126 \mathrm{MHz} \mathrm{CDCl}_{3}\right) \delta 13.9,22.2$, 23.8, 26.0, 36.4, 50.5, $120.6\left(\mathrm{q}, J_{\mathrm{CF}}=6 \mathrm{~Hz}\right), 123.7\left(\mathrm{q}, J_{\mathrm{CF}}=277\right.$ $\mathrm{Hz}), 142.7$ (q, $\left.J_{\mathrm{CF}}=28 \mathrm{~Hz}\right), 210.5 ;{ }^{19} \mathrm{~F} \mathrm{NMR}\left(470 \mathrm{MHz}, \mathrm{CDC1}_{3}\right)$

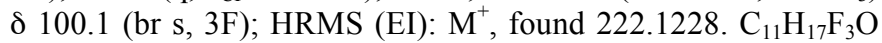
requires 222.1231 .

\subsection{2-Methyl-2-(3,3,3-trifluoroprop-1-en-2-yl)cyclohexan-1- one (1f)}

Compound 1f was prepared by the method described for 1a using ketone $\mathbf{6 f}(986 \mathrm{mg}, 5.13 \mathrm{mmol})$ and methyl trifluoromethanesulfonate $(0.87 \mathrm{~mL}, 7.7 \mathrm{mmol})$. Purification by column chromatography (hexane/ethyl acetate $=5 / 1$ ) gave $\mathbf{1 f}$ (535 mg, 51\%) as a colorless oil; [Found: C, 58.20; H, 6.49. $\mathrm{C}_{10} \mathrm{H}_{13} \mathrm{~F}_{3} \mathrm{O}$ requires $\mathrm{C}, 58.25 ; \mathrm{H}, 6.35 \%$ ]; IR (neat) $v 2945,2871$, 1716, 1319, 1174, 1124, 957, 912, $744 \mathrm{~cm}^{-1} ;{ }^{1} \mathrm{H}$ NMR $(500 \mathrm{MHz}$, $\left.\mathrm{CDC}_{3}\right) \delta 1.32(\mathrm{~s}, 3 \mathrm{H}), 1.59-1.66(\mathrm{~m}, 1 \mathrm{H}), 1.69-1.77(\mathrm{~m}, 1 \mathrm{H})$, $1.77-1.86(\mathrm{~m}, 2 \mathrm{H}), 1.91-2.00(\mathrm{~m}, 1 \mathrm{H}), 2.32-2.38(\mathrm{~m}, 1 \mathrm{H}), 2.39-$ $2.45(\mathrm{~m}, 1 \mathrm{H}), 2.49-2.56(\mathrm{~m}, 1 \mathrm{H}), 5.58\left(\mathrm{q}, J_{\mathrm{HF}}=1.1 \mathrm{~Hz}, 1 \mathrm{H}\right), 5.95$ $\left(\mathrm{q}, J_{\mathrm{HF}}=1.1 \mathrm{~Hz}, 1 \mathrm{H}\right) ;{ }^{13} \mathrm{C} \mathrm{NMR}\left(126 \mathrm{MHz}, \mathrm{CDCl}_{3}\right) \delta 21.5,24.3$, 27.6, 38.2, 39.4, 52.6, 121.1 (q, $\left.J_{\mathrm{CF}}=6 \mathrm{~Hz}\right), 121.5$ (q, $J_{\mathrm{CF}}=275$ $\mathrm{Hz}), 141.0\left(\mathrm{q}, J_{\mathrm{CF}}=28 \mathrm{~Hz}\right), 211.0 ;{ }^{19} \mathrm{~F} \mathrm{NMR}\left(470 \mathrm{MHz}, \mathrm{CDC}_{3}\right)$ $\delta 101.2$ (br s, 3F).

\subsection{3,3-Dimethyl-6-phenyl-2-(trifluoromethyl)hept-1-en-4-one} (1b)

To a DMF (7.5 mL) suspension of 3-phenylbutanal $(1.00 \mathrm{~g}$, $6.74 \mathrm{mmol})$, cesium fluoride $(249 \mathrm{mg}, 1.64 \mathrm{mmol})$, and molecular sieves 4A $(220 \mathrm{mg})$ was added a DMF $(7.5 \mathrm{~mL})$ solution of trimethyl[(trifluoromethyl)allyl]silane (1.31 g, 7.19 $\mathrm{mmol}$ ). After stirring at room temperature for $26 \mathrm{~h}$, the reaction was quenched with an aqueous $\mathrm{HCl}$ solution $(1 \mathrm{M})$. The organic materials were extracted with diethyl ether three times. The combined organic extracts were washed with brine and dried over $\mathrm{Na}_{2} \mathrm{SO}_{4}$. After the solvent was removed under reduced pressure, the residue was purified by column chromatography (heptane/ethyl acetate $=3 / 1$ ) to give a crude mixture (594 mg) including 6-phenyl-2-(trifluoromethyl)hept-1-en-4-ol (5b) as a pale yellow oil.

To a dichloromethane $(6.9 \mathrm{~mL})$ solution of the obtained crude mixture were added pyridinium chlorochromate $(756 \mathrm{mg}, 3.51$ $\mathrm{mmol})$ and silica gel $(756 \mathrm{mg})$. After stirring at room temperature for $19 \mathrm{~h}$, the mixture was filtered through a pad of Celite (dichloromethane). After the solvent was removed under reduced 
pressure, the residue was purified by column chromatography (pentane/diethyl ether $=6 / 1)$ to give a crude mixture $(548 \mathrm{mg}$ ) including 6-phenyl-2-(trifluoromethyl)hept-1-en-4-one (6b) as a pale yellow oil.

To a diethyl ether $(12 \mathrm{~mL})$ solution of the obtained crude mixture was added potassium tert-butoxide $(264 \mathrm{mg}, 2.35 \mathrm{mmol})$ at $-78{ }^{\circ} \mathrm{C}$. After stirring at $-78{ }^{\circ} \mathrm{C}$ for $1 \mathrm{~h}$, methyl trifluoromethanesulfonate $(0.37 \mathrm{~mL}, 3.3 \mathrm{mmol})$ was added to the mixture. After stirring at $-78{ }^{\circ} \mathrm{C}$ for $20 \mathrm{~min}$, the mixture was warmed to room temperature and stirred for another $23 \mathrm{~h}$. The reaction was quenched with phosphate buffer $(\mathrm{pH} 7)$. The organic materials were extracted with diethyl ether three times. The combined organic extracts were washed with brine and dried over $\mathrm{Na}_{2} \mathrm{SO}_{4}$. After the solvent was removed under reduced pressure, the residue was purified by column chromatography (heptane/ethyl acetate $=6 / 1)$ to give a crude mixture $(552 \mathrm{mg}$ ) including 3-methyl-6-phenyl-2-(trifluoromethyl)hept-1-en-4-one (7b) as a pale yellow oil.

To a diethyl ether $(14 \mathrm{~mL})$ solution of the obtained crude mixture was added dropwise a toluene solution of potassium hexamethyldisilazide $(0.50 \mathrm{M}, 3.16 \mathrm{~mL}, 1.6 \mathrm{mmol})$ at $-100{ }^{\circ} \mathrm{C}$. After stirring at $-100{ }^{\circ} \mathrm{C}$ for $30 \mathrm{~min}$, methyl trifluoromethanesulfonate $(0.18 \mathrm{~mL}, 1.6 \mathrm{mmol})$ was added to the mixture at $-100{ }^{\circ} \mathrm{C}$. After stirring for $10 \mathrm{~min}$ at $-100{ }^{\circ} \mathrm{C}$, the reaction mixture was warmed to room temperature and stirred for another $14 \mathrm{~h}$. The reaction was quenched with phosphate buffer $(\mathrm{pH} 7)$. The organic materials were extracted with diethyl ether three times. The combined organic extracts were washed with brine and dried over $\mathrm{Na}_{2} \mathrm{SO}_{4}$. After the solvent was removed under reduced pressure, the residue was purified by preparative thin-layer chromatography (heptane/ethyl acetate $=8 / 1$ ) to give 1b $(352 \mathrm{mg}, 18 \%)$ as a pale yellow oil; [Found: C, 67.51; H, 6.77. $\mathrm{C}_{16} \mathrm{H}_{19} \mathrm{~F}_{3} \mathrm{O}$ requires $\mathrm{C}, 67.59 ; \mathrm{H}, 6.74 \%$ ]; IR (neat) $v 2972,1716$, 1454, 1327, 1173, 1113, 953, 760, $698 \mathrm{~cm}^{-1}$; ${ }^{1} \mathrm{H}$ NMR $(400 \mathrm{MHz}$, $\left.\mathrm{CDC}_{3}\right) \delta 1.17(\mathrm{~s}, 3 \mathrm{H}), 1.23(\mathrm{~d}, J=7.2 \mathrm{~Hz}, 3 \mathrm{H}), 1.28(\mathrm{~s}, 3 \mathrm{H})$, $2.61(\mathrm{dd}, J=17.6,7.6 \mathrm{~Hz}, 1 \mathrm{H}), 2.71(\mathrm{dd}, J=17.6,6.4 \mathrm{~Hz}, 1 \mathrm{H})$, $3.31-3.40(\mathrm{~m}, 1 \mathrm{H}), 5.48\left(\mathrm{q}, J_{\mathrm{HF}}=0.8 \mathrm{~Hz}, 1 \mathrm{H}\right), 5.88\left(\mathrm{q}, J_{\mathrm{HF}}=0.8\right.$ $\mathrm{Hz}, 1 \mathrm{H}), 7.16-7.20(\mathrm{~m}, 3 \mathrm{H}), 7.26-7.30(\mathrm{~m}, 2 \mathrm{H}) ;{ }^{13} \mathrm{C}$ NMR $(126$ $\left.\mathrm{MHz}, \mathrm{CDCl}_{3}\right) \delta 21.4,23.4,23.6,34.8,45.6,50.4,120.9$ (q, $J_{\mathrm{CF}}=$ $6 \mathrm{~Hz}), 123.6\left(\mathrm{q}, J_{\mathrm{CF}}=277 \mathrm{~Hz}\right), 126.2,126.9,128.4,142.3\left(\mathrm{q}, J_{\mathrm{CF}}\right.$ $=27 \mathrm{~Hz}), 146.4,208.6 ;{ }^{19} \mathrm{~F}$ NMR $\left(470 \mathrm{MHz}, \mathrm{CDCl}_{3}\right) \delta 100.3(\mathrm{br}$ $\mathrm{s}, 3 \mathrm{~F})$.

4.16. 3-Phenyl-1-[1-(3,3,3-trifluoroprop-1-en-2yl)cyclopentyl]propan-1-one (1h)

To a diethyl ether $(8.3 \mathrm{~mL})$ solution of ketone $6 \mathrm{e}(391 \mathrm{mg}$, $1.61 \mathrm{mmol}$ ) was dropwise added a toluene solution of potassium hexamethyldisilazide $(0.50 \mathrm{M}, 3.40 \mathrm{~mL}, 1.7 \mathrm{mmol})$ at $-78{ }^{\circ} \mathrm{C}$. After strirring at $0{ }^{\circ} \mathrm{C}$ for $10 \mathrm{~min}$, the mixture was added to a diethyl ether $(8.3 \mathrm{~mL})$ solution of 1,4-diiodobutane $(0.43 \mathrm{~mL}, 3.3$ $\mathrm{mmol})$ and hexamethylphosphoramide $(2.7 \mathrm{~mL})$ at $-78{ }^{\circ} \mathrm{C}$. The mixture was warmed to room temperature. After stirring for $7 \mathrm{~h}$, the reaction was quenched with phosphate buffer $(\mathrm{pH} 7)$. The organic materials were extracted with ethyl acetate three times. The combined organic extracts were washed with brine and dried over $\mathrm{Na}_{2} \mathrm{SO}_{4}$. After the solvent was removed under reduced pressure, the residue was purified by column chromatography (hexane/ethyl acetate $=10 / 1)$ to give a crude mixture $(372 \mathrm{mg})$ including 8-iodo-1-phenyl-4-(3,3,3-trifluoroprop-1-en-2yl)octan-3-one as a colorless oil.

To a diethyl ether $(3.1 \mathrm{~mL})$ solution of the obtained crude mixture was added dropwise a toluene solution of potassium hexamethyldisilazide $(0.50 \mathrm{M}, 1.30 \mathrm{~mL}, 0.65 \mathrm{mmol})$ at $-78^{\circ} \mathrm{C}$. After stirring at $-78{ }^{\circ} \mathrm{C}$ for $5 \mathrm{~min}$, the mixture was warmed to room temperature and stirred for another $4 \mathrm{~h}$. The reaction was quenched with phosphate buffer $(\mathrm{pH} 7)$. The organic materials were extracted with ethyl acetate three times. The combined organic extracts were washed with brine and dried over $\mathrm{Na}_{2} \mathrm{SO}_{4}$. After the solvent was removed under reduced pressure, the residue was purified by column chromatography (hexane/ethyl acetate $=10 / 1)$ to give $\mathbf{1 h}(257 \mathrm{mg}, 54 \%)$ as a colorless oil; [Found: C, 69.05; H, 6.46. $\mathrm{C}_{17} \mathrm{H}_{19} \mathrm{~F}_{3} \mathrm{O}$ requires $\mathrm{C}, 68.90 ; \mathrm{H}$, $6.46 \%$ ]; IR (neat) v 2960, 1712, 1454, 1323, 1167, 1120, 748, $698 \mathrm{~cm}^{-1}$; ${ }^{1} \mathrm{H}$ NMR $\left(500 \mathrm{MHz}, \mathrm{CDCl}_{3}\right) \delta 1.49-1.58(\mathrm{~m}, 2 \mathrm{H})$, $1.59-1.67(\mathrm{~m}, 2 \mathrm{H}), 1.68-1.76(\mathrm{~m}, 2 \mathrm{H}), 2.12-2.18(\mathrm{~m}, 2 \mathrm{H}), 2.70$ $(\mathrm{t}, J=7.8 \mathrm{~Hz}, 2 \mathrm{H}), 2.86(\mathrm{t}, J=7.8 \mathrm{~Hz}, 2 \mathrm{H}), 5.59\left(\mathrm{q}, J_{\mathrm{HF}}=1.0 \mathrm{~Hz}\right.$, $1 \mathrm{H}), 5.89\left(\mathrm{q}, J_{\mathrm{HF}}=1.0 \mathrm{~Hz}, 1 \mathrm{H}\right), 7.14-7.18(\mathrm{~m}, 2 \mathrm{H}), 7.18-7.21(\mathrm{~m}$, 1H), 7.24-7.29 (m, 2H); ${ }^{13} \mathrm{C}$ NMR (126 MHz, $\left.\mathrm{CDCl}_{3}\right) \delta 23.2$, $30.3,33.2,38.9,62.5,120.7$ (q, $\left.J_{\mathrm{CF}}=6 \mathrm{~Hz}\right), 123.6$ (q, $J_{\mathrm{CF}}=276$ $\mathrm{Hz}), 126.1,128.39,128.43,140.9$ (q, $J_{\mathrm{CF}}=28 \mathrm{~Hz}$ ), 141.1, 207.6; ${ }^{19} \mathrm{~F} \mathrm{NMR}\left(470 \mathrm{MHz}, \mathrm{CDCl}_{3}\right) \delta 99.4$ (br s, 3F).

\subsection{2-Cyclohexyl-1-[1-(3,3,3-trifluoroprop-1-en-2- yl)cyclopentyl]ethan-1-one (1g)}

Compound $\mathbf{1 g}$ was prepared by the method described for $\mathbf{1 h}$ using ketone 6a (500 mg, $2.13 \mathrm{mmol})$ and 1,4-diiodobutane (0.57 $\mathrm{mL}, 4.3 \mathrm{mmol})$. Purification by column chromatography (heptane/ethyl acetate $=20 / 1)$ gave $1 \mathrm{~g}(456 \mathrm{mg}, 74 \%)$ as a colorless liquid; [Found: $\mathrm{C}, 66.65 ; \mathrm{H}, 7.99 . \mathrm{C}_{16} \mathrm{H}_{23} \mathrm{~F}_{3} \mathrm{O}$ requires $\mathrm{C}$, 66.65; H, 8.04\%]; IR (neat) v 2924, 2852, 1448, 1410, 1323, $1167,1120,945,677 \mathrm{~cm}^{-1}$; ${ }^{1} \mathrm{H}$ NMR $\left(400 \mathrm{MHz}, \mathrm{CDC1}_{3}\right) \delta 0.78-$ $0.88(\mathrm{~m}, 2 \mathrm{H}), 1.05-1.16(\mathrm{~m}, 1 \mathrm{H}), 1.21-1.32(\mathrm{~m}, 2 \mathrm{H}), 1.57-1.78$ $(\mathrm{m}, 11 \mathrm{H}), 1.79-1.90(\mathrm{~m}, 1 \mathrm{H}), 2.18-2.22(\mathrm{~m}, 2 \mathrm{H}), 2.26(\mathrm{~d}, J=6.4$ $\mathrm{Hz}, 2 \mathrm{H}), 5.64\left(\mathrm{q}, J_{\mathrm{HF}}=1.2 \mathrm{~Hz}, 1 \mathrm{H}\right), 5.92\left(\mathrm{q}, J_{\mathrm{HF}}=0.8 \mathrm{~Hz}, 1 \mathrm{H}\right)$; ${ }^{13} \mathrm{C}$ NMR $\left(126 \mathrm{MHz}, \mathrm{CDCl}_{3}\right) \delta 23.3,26.1,26.3,33.0,33.1,33.2$, 44.5, 62.6, $120.6\left(\mathrm{q}, J_{\mathrm{CF}}=6 \mathrm{~Hz}\right), 123.7\left(\mathrm{q}, J_{\mathrm{CF}}=277 \mathrm{~Hz}\right), 141.2$ $\left(\mathrm{q}, J_{\mathrm{CF}}=28 \mathrm{~Hz}\right), 207.8 ;{ }^{19} \mathrm{~F} \mathrm{NMR}\left(470 \mathrm{MHz}, \mathrm{CDC1}_{3}\right) \delta 99.7$ (br s, $3 \mathrm{~F})$.

\subsection{2-Cyclohexyl-1-[1-(3,3,3-trifluoroprop-1-en-2- yl)cyclohexyl]ethan-1-one (1i)}

Compound 1i was prepared by the method described for $\mathbf{1 h}$ using ketone 6a (500 mg, $2.13 \mathrm{mmol})$ and 1,5-diiodopentane (0.63 mL, $4.3 \mathrm{mmol})$. Purification by column chromatography (heptane/ethyl acetate $=20 / 1)$ gave $1 \mathbf{i}(548 \mathrm{mg}, 85 \%)$ as a pale yellow oil; [Found: $\mathrm{C}, 67.42 ; \mathrm{H}, 8.27 . \mathrm{C}_{17} \mathrm{H}_{25} \mathrm{~F}_{3} \mathrm{O}$ requires $\mathrm{C}$, 67.53; H, 8.33\%]; IR (neat) v 2924, 2854, 1714, 1448, 1317, 1282, 1161, 1120, 951, 901, 741, $700 \mathrm{~cm}^{-1}$; ${ }^{1} \mathrm{H}$ NMR $(400 \mathrm{MHz}$, $\left.\mathrm{CDC}_{3}\right) \delta 0.77-0.87(\mathrm{~m}, 2 \mathrm{H}), 1.06-1.15(\mathrm{~m}, 1 \mathrm{H}), 1.19-1.32(\mathrm{~m}$, $2 \mathrm{H}), 1.39-1.45(\mathrm{~m}, 2 \mathrm{H}), 1.49-1.55(\mathrm{~m}, 4 \mathrm{H}), 1.61-1.67(\mathrm{~m}, 5 \mathrm{H})$, $1.75-1.89(\mathrm{~m}, 3 \mathrm{H}), 1.93-2.00(\mathrm{~m}, 2 \mathrm{H}), 2.23(\mathrm{~d}, J=6.4 \mathrm{~Hz}, 2 \mathrm{H})$, $5.64\left(\mathrm{q}, J_{\mathrm{HF}}=1.2 \mathrm{~Hz}, 1 \mathrm{H}\right), 6.08(\mathrm{br} \mathrm{s}, 1 \mathrm{H}) ;{ }^{13} \mathrm{C} \mathrm{NMR}(126 \mathrm{MHz}$, $\left.\mathrm{CDCl}_{3}\right) \delta 22.2,25.7,26.1,26.3,31.6,32.9,33.1,44.3,54.8$, $123.0\left(\mathrm{q}, J_{\mathrm{CF}}=6 \mathrm{~Hz}\right), 123.7\left(\mathrm{q}, J_{\mathrm{CF}}=277 \mathrm{~Hz}\right), 140.3\left(\mathrm{q}, J_{\mathrm{CF}}=27\right.$ $\mathrm{Hz}), 209.1 ;{ }^{19} \mathrm{~F} \mathrm{NMR}\left(470 \mathrm{MHz}, \mathrm{CDCl}_{3}\right) \delta 100.0$ (br s, 3F).

\subsection{3-Phenyl-1-[1-(3,3,3-trifluoroprop-1-en-2- yl)cyclohexyl]butan-1-one (1j)}

Compound $\mathbf{1 j}$ was prepared by the method described for $\mathbf{1 h}$ using ketone $\mathbf{6 b}(410 \mathrm{mg}, 1.60 \mathrm{mmol})$ and 1,5-diiodopentane (0.48 $\mathrm{mL}, 3.2 \mathrm{mmol})$. Purification by column chromatography (heptane/ethyl acetate $=10 / 1)$ gave $\mathbf{1 j}(392 \mathrm{mg}, 76 \%)$ as a pale yellow oil; IR (neat) $v 2866,1712,1454,1317,1161,1122,760$, $698 \mathrm{~cm}^{-1}$; ${ }^{1} \mathrm{H}$ NMR $\left(400 \mathrm{MHz}, \mathrm{CDC1}_{3}\right) \delta 1.21(\mathrm{~d}, J=6.8 \mathrm{~Hz}$, $3 \mathrm{H}), 1.30-1.54(\mathrm{~m}, 6 \mathrm{H}), 1.66-1.87(\mathrm{~m}, 3 \mathrm{H}), 1.96-2.02(\mathrm{~m}, 1 \mathrm{H})$, $2.59(\mathrm{dd}, J=17.8,7.8 \mathrm{~Hz}, 1 \mathrm{H}), 2.69(\mathrm{dd}, J=17.8,6.2 \mathrm{~Hz}, 1 \mathrm{H})$, $3.35(\mathrm{dqd}, J=7.8,6.8,6.2 \mathrm{~Hz}, 1 \mathrm{H}), 5.47\left(\mathrm{q}, J_{\mathrm{HF}}=1.6 \mathrm{~Hz}, 1 \mathrm{H}\right)$, 5.98 (br s, $1 \mathrm{H}) ;{ }^{13} \mathrm{C}$ NMR $\left(126 \mathrm{MHz}, \mathrm{CDCl}_{3}\right) \delta 21.5,22.1,22.2$, $25.6,31.3,31.7,34.6,45.6,54.7,123.2\left(\mathrm{q}, J_{\mathrm{CF}}=6 \mathrm{~Hz}\right), 123.6(\mathrm{q}$, 
$\left.J_{\mathrm{CF}}=277 \mathrm{~Hz}\right), 126.2,127.0,128.4,139.9\left(\mathrm{q}, J_{\mathrm{CF}}=27 \mathrm{~Hz}\right)$, 146.5, 208.1; ${ }^{19} \mathrm{~F}$ NMR (470 MHz, $\left.\mathrm{CDC1}_{3}\right) \delta 100.0$ (br s, 3F); HRMS (EI): $\mathrm{M}^{+}$, found 324.1710. $\mathrm{C}_{19} \mathrm{H}_{23} \mathrm{~F}_{3} \mathrm{O}$ requires 324.1701.

4.20. N-[3,3-Dimethyl-2-(trifluoromethyl)oct-1-en-4-ylidene]-4methylbenzenesulfonamide (2d)

To a 1,2-dichloroethane $(15 \mathrm{~mL})$ solution of ketone $\mathbf{1 d}$ (335 $\mathrm{mg}, 1.51 \mathrm{mmol})$ and 4-methylbenzenesulfonamide (313 $\mathrm{mg}, 1.83$ mmol) was added triethylamine $(0.32 \mathrm{~mL}, 2.3 \mathrm{mmol})$ at $0{ }^{\circ} \mathrm{C}$. After stirring at $0{ }^{\circ} \mathrm{C}$ for $5 \mathrm{~min}, \mathrm{TiCl}_{4}(0.33 \mathrm{~mL}, 3.0 \mathrm{mmol})$ was added dropwise to the mixture at $0{ }^{\circ} \mathrm{C}$. After the mixture was refluxed for $36 \mathrm{~h}$, the reaction was quenched with phosphate buffer $(\mathrm{pH} \mathrm{7)}$ at room temperature. The reaction mixture was filtered through a pad of Celite. The organic materials were extracted with dichloromethane three times. The combined organic extracts were washed with brine and dried over $\mathrm{Na}_{2} \mathrm{SO}_{4}$. After the solvent was removed under reduced pressure, the residue was purified by column chromatography (pentane/diethyl ether $=5 / 1)$ to give $\mathbf{2 d}(210 \mathrm{mg}, 37 \%)$ as a colorless crystal; IR (neat) $v 2960,2918,1616,1321,1157,1124,1090,908,731$, $667,559 \mathrm{~cm}^{-1} ;{ }^{1} \mathrm{H}$ NMR $\left(500 \mathrm{MHz}, \mathrm{CDCl}_{3}\right) \delta 0.94(\mathrm{t}, J=7.3 \mathrm{~Hz}$ $3 \mathrm{H}), 1.36(\mathrm{~s}, 6 \mathrm{H}), 1.39-1.48(\mathrm{~m}, 2 \mathrm{H}), 1.71-1.78(\mathrm{~m}, 2 \mathrm{H}), 2.43(\mathrm{~s}$, $3 \mathrm{H}), 2.77-2.81(\mathrm{~m}, 2 \mathrm{H}), 5.59(\mathrm{br} \mathrm{s}, 1 \mathrm{H}), 5.92(\mathrm{br} \mathrm{s}, 1 \mathrm{H}), 7.31(\mathrm{~d}$, $J=8.2 \mathrm{~Hz}, 2 \mathrm{H}), 7.83(\mathrm{~d}, J=8.2 \mathrm{~Hz}, 2 \mathrm{H}) ;{ }^{13} \mathrm{C}$ NMR $(126 \mathrm{MHz}$, $\left.\mathrm{CDCl}_{3}\right) \delta 13.5,21.6,23.6,25.1,31.2,33.6,49.7,121.2\left(\mathrm{q}, J_{\mathrm{CF}}=6\right.$ $\mathrm{Hz}), 123.5\left(\mathrm{q}, J_{\mathrm{CF}}=277 \mathrm{~Hz}\right), 126.9,129.3,138.4,142.7\left(\mathrm{q}, J_{\mathrm{CF}}=\right.$ $28 \mathrm{~Hz}), 143.4,192.9 ;{ }^{19} \mathrm{~F}$ NMR $\left(470 \mathrm{MHz}, \mathrm{CDC1}_{3}\right) \delta 100.6$ (br s, 3F); HRMS (ESI+): $\mathrm{MNa}^{+}$, found 398.1377. $\mathrm{C}_{18} \mathrm{H}_{24} \mathrm{~F}_{3} \mathrm{NNaO}_{2} \mathrm{~S}$ requires 398.1378 .

4.21. N-[1-Cyclohexyl-3,3-dimethyl-4-(trifluoromethyl)pent-4-en2-ylidene]-4-methylbenzenesulfonamide (2a)

Compound 2a was prepared by the method described for $\mathbf{2 d}$ using ketone 1a $(303 \mathrm{mg}, 1.15 \mathrm{mmol})$ and 4methylbenzenesulfonamide ( $237 \mathrm{mg}, 1.38 \mathrm{mmol})$. Purification by column chromatography (hexane/ethyl acetate $=10 / 1$ ) gave $\mathbf{2 a}$ $(81 \mathrm{mg}, 17 \%)$ as a colorless crystal; IR (neat) $v 2929,2854,1616$ $1321,1157,1126,1090,814,739,673 \mathrm{~cm}^{-1} ;{ }^{1} \mathrm{H}$ NMR $(500 \mathrm{MHz}$, $\left.\mathrm{CDC1}_{3}\right) \delta 1.01-1.11(\mathrm{~m}, 1 \mathrm{H}), 1.11-1.19(\mathrm{~m}, 1 \mathrm{H}), 1.24-1.32(\mathrm{~m}$, $2 \mathrm{H}), 1.36(\mathrm{~s}, 6 \mathrm{H}), 1.62-1.68(\mathrm{~m}, 1 \mathrm{H}), 1.70-1.79(\mathrm{~m}, 5 \mathrm{H}), 2.08$ $2.18(\mathrm{~m}, 1 \mathrm{H}), 2.43(\mathrm{~s}, 3 \mathrm{H}), 2.74(\mathrm{~d}, J=7.5 \mathrm{~Hz}, 2 \mathrm{H}), 5.56(\mathrm{br} \mathrm{s}$, $1 \mathrm{H}), 5.87$ (br s, 1H), 7.29 (d, $J=8.2 \mathrm{~Hz}, 2 \mathrm{H}), 7.81(\mathrm{~d}, J=8.2 \mathrm{~Hz}$, $2 \mathrm{H}) ;{ }^{13} \mathrm{C}$ NMR $\left(126 \mathrm{MHz}, \mathrm{CDCl}_{3}\right) \delta 21.6,25.4,26.0,26.4,33.7$, $38.0,41.4,49.6,121.0\left(\mathrm{q}, J_{\mathrm{CF}}=6 \mathrm{~Hz}\right), 123.6\left(\mathrm{q}, J_{\mathrm{CF}}=277 \mathrm{~Hz}\right)$, $126.9,129.3,138.6,143.19\left(\mathrm{q}, J_{\mathrm{CF}}=27 \mathrm{~Hz}\right), 143.21,192.3 ;{ }^{19} \mathrm{~F}$ NMR (470 MHz, $\left.\mathrm{CDC1}_{3}\right) \delta 101.1$ (br s, 3F); HRMS (ESI+): $\mathrm{MNa}^{+}$, found $438.1700 . \mathrm{C}_{21} \mathrm{H}_{29} \mathrm{~F}_{3} \mathrm{NNaO}_{2} \mathrm{~S}$ requires 438.1691 .

4.22. N-[4,4-Dimethyl-1-phenyl-5-(trifluoromethyl)hex-5-en-3ylidene]-4-methylbenzenesulfonamide (2e)

Compound 2e was prepared by the method described for $\mathbf{2 d}$ using ketone 1e $(620 \mathrm{mg}, 2.29 \mathrm{mmol})$ and 4methylbenzenesulfonamide (392 mg, $2.29 \mathrm{mmol})$. Purification by column chromatography (hexane/ethyl acetate $=5 / 1$ ) gave $\mathbf{2 e}$ (534 $\mathrm{mg}, 55 \%)$ as a colorless oil; [Found: $\mathrm{C}, 62.53 ; \mathrm{H}, 5.83 ; \mathrm{N}$, 3.25. $\mathrm{C}_{22} \mathrm{H}_{24} \mathrm{~F}_{3} \mathrm{NO}_{2} \mathrm{~S}$ requires $\mathrm{C}, 62.39 ; \mathrm{H}, 5.71 ; \mathrm{N}, 3.31 \%$ ]; IR (neat) $v 2985,2946,1770,1616,1456,1412,1321,1240,1157$, 1126, 1090, 816, 741, 675, $552 \mathrm{~cm}^{-1}$; ${ }^{1} \mathrm{H}$ NMR $(500 \mathrm{MHz}$, $\left.\mathrm{CDC1}_{3}\right) \delta 1.39(\mathrm{~s}, 6 \mathrm{H}), 2.44(\mathrm{~s}, 3 \mathrm{H}), 3.09(\mathrm{~s}, 4 \mathrm{H}), 5.61\left(\mathrm{q}, J_{\mathrm{HF}}=\right.$ $1.2 \mathrm{~Hz}, 1 \mathrm{H}), 5.95\left(\mathrm{q}, J_{\mathrm{HF}}=1.1 \mathrm{~Hz}, 1 \mathrm{H}\right), 7.20-7.33(\mathrm{~m}, 7 \mathrm{H}), 7.87$ $(\mathrm{d}, J=8.3 \mathrm{~Hz}, 2 \mathrm{H}) ;{ }^{13} \mathrm{C} \mathrm{NMR}\left(126 \mathrm{MHz}, \mathrm{CDCl}_{3}\right) \delta 21.6,25.0$, $35.0,36.0,49.8,121.5$ (q, $\left.J_{\mathrm{CF}}=6 \mathrm{~Hz}\right), 123.5\left(\mathrm{q}, J_{\mathrm{CF}}=277 \mathrm{~Hz}\right)$, $126.5,127.0,128.3,128.6,129.4,138.2,140.5,142.5\left(\mathrm{q}, J_{\mathrm{CF}}=\right.$ $28 \mathrm{~Hz}), 143.6,191.1 ;{ }^{19} \mathrm{~F}$ NMR $\left(470 \mathrm{MHz}, \mathrm{CDC1}_{3}\right) \delta 100.7$ (br s, $3 \mathrm{~F})$.
4.23. 4-Methyl-N-[2-Methyl-2-(3,3,3-trifluoroprop-1-en-2yl)cyclohexylidene]benzenesulfonamide (2f)

Compound $\mathbf{2 f}$ was prepared by the method described for $\mathbf{2 d}$ using ketone 1f (414 $\mathrm{mg}, 2.01 \mathrm{mmol})$ and 4methylbenzenesulfonamide ( $344 \mathrm{mg}, 2.01 \mathrm{mmol}$ ). Purification by column chromatography (hexane/ethyl acetate $=5 / 1$ ) gave a $1: 1$ mixture of $\mathbf{2 f}$ and its enamine form (587 $\mathrm{mg}, 81 \%)$ as a white solid; [(1:1 mixture) Found: C, 56.48; H, 5.60; N, 3.70. $\mathrm{C}_{17} \mathrm{H}_{20} \mathrm{~F}_{3} \mathrm{NO}_{2} \mathrm{~S}$ requires $\mathrm{C}, 56.81 ; \mathrm{H}, 5.61 ; \mathrm{N}, 3.90 \%$ ]; IR (neat) $v$ (1:1 mixture) 3290, 2939, 1622, 1408, 1323, 1157, 1128, 1090, $814,739,667 \mathrm{~cm}^{-1} ;{ }^{1} \mathrm{H}$ NMR $\left(500 \mathrm{MHz}, \mathrm{CDCl}_{3}\right) \delta(1: 1$ mixture $)$ $1.08\left(\mathrm{q}, J_{\mathrm{HF}}=1.6 \mathrm{~Hz}, 1.5 \mathrm{H}\right), 1.30(\mathrm{~s}, 1.5 \mathrm{H}), 1.32-1.41(\mathrm{~m}, 0.5 \mathrm{H})$, $1.42-1.47(\mathrm{~m}, 0.5 \mathrm{H}), 1.47-1.55(\mathrm{~m}, 0.5 \mathrm{H}), 1.62-1.89(\mathrm{~m}, 2.5 \mathrm{H})$, $1.95-2.02(\mathrm{~m}, 0.5 \mathrm{H}), 2.02-2.06(\mathrm{~m}, 1 \mathrm{H}), 2.36-2.42(\mathrm{~m}, 0.5 \mathrm{H})$, $2.436(\mathrm{~s}, 1.5 \mathrm{H}), 2.442(\mathrm{~s}, 1.5 \mathrm{H}), 2.79$ (ddd, $J=14.2,10.6,5.0 \mathrm{~Hz}$, $0.5 \mathrm{H}), 3.43(\mathrm{ddd}, J=14.2,5.6,4.0 \mathrm{~Hz}, 0.5 \mathrm{H}), 5.32\left(\mathrm{q}, J_{\mathrm{HF}}=1.9\right.$ $\mathrm{Hz}, 0.5 \mathrm{H}), 5.46$ (br s, 0.5H), 5.52-5.53 (m, 0.5H), 5.83 (dd, $J=$ $4.2,4.2 \mathrm{~Hz}, 0.5 \mathrm{H}), 5.85\left(\mathrm{q}, J_{\mathrm{HF}}=1.2 \mathrm{~Hz}, 0.5 \mathrm{H}\right), 5.92-5.93(\mathrm{~m}$, $0.5 \mathrm{H}), 7.29-7.31(\mathrm{~m}, 1 \mathrm{H}), 7.31-7.33(\mathrm{~m}, 1 \mathrm{H}), 7.74(\mathrm{~d}, J=8.3 \mathrm{~Hz}$, $1 \mathrm{H}), 7.84(\mathrm{~d}, J=8.3 \mathrm{~Hz}, 1 \mathrm{H}) ;{ }^{13} \mathrm{C}$ NMR $\left(126 \mathrm{MHz}, \mathrm{CDCl}_{3}\right) \delta$ (1:1 mixture) 17.2, 21.4, 21.6, 23.0, 24.1, 26.2, 27.9, 33.7, 36.7, $39.0,42.0,50.5,113.9,121.6\left(\mathrm{q}, J_{\mathrm{CF}}=13 \mathrm{~Hz}\right), 123.3\left(\mathrm{q}, J_{\mathrm{CF}}=14\right.$ $\mathrm{Hz}), 123.6\left(\mathrm{q}, J_{\mathrm{CF}}=277 \mathrm{~Hz}\right), 123.8\left(\mathrm{q}, J_{\mathrm{CF}}=277 \mathrm{~Hz}\right), 126.9$, $127.5,129.3,129.5,134.3,136.6,138.5,140.7\left(\mathrm{q}, J_{\mathrm{CF}}=26 \mathrm{~Hz}\right)$, $142.3\left(\mathrm{q}, J_{\mathrm{CF}}=27 \mathrm{~Hz}\right), 143.4,143.9,193.7 ;{ }^{19} \mathrm{~F} \mathrm{NMR}(470 \mathrm{MHz}$, $\left.\mathrm{CDC1}_{3}\right) \delta(1: 1$ mixture) 101.0 (br s, 1.5F), 101.4 (br s, 1.5F).

\subsection{4-Methyl-N-\{3-phenyl-1-[1-(3,3,3-trifluoroprop-1-en-2-} yl)cyclopentyl]propylidene\}benzenesulfonamide (2h)

Compound $\mathbf{2 h}$ was prepared by the method described for $\mathbf{2 d}$ using ketone $\mathbf{1 h} \quad(500 \mathrm{mg}, 1.69 \mathrm{mmol})$ and 4methylbenzenesulfonamide ( $289 \mathrm{mg}, 1.69 \mathrm{mmol})$. Purification by column chromatography (hexane/ethyl acetate $=5 / 1$ ) gave $\mathbf{2 h}$ $(232 \mathrm{mg}, 31 \%)$ as a colorless crystal; IR (neat) v 2960, 1616, 1456, 1319, 1159, 1128, 1092, 912, 814, $742 \mathrm{~cm}^{-1}$; ${ }^{1} \mathrm{H}$ NMR (500 $\left.\mathrm{MHz}, \mathrm{CDC1}_{3}\right) \delta 1.55-1.69(\mathrm{~m}, 4 \mathrm{H}), 1.77-1.85(\mathrm{~m}, 2 \mathrm{H}), 2.18-$ $2.24(\mathrm{~m}, 2 \mathrm{H}), 2.45(\mathrm{~s}, 3 \mathrm{H}), 3.02-3.11(\mathrm{~m}, 4 \mathrm{H}), 5.68(\mathrm{br} \mathrm{s}, 1 \mathrm{H})$, $6.01(\mathrm{br} \mathrm{s}, 1 \mathrm{H}), 7.20-7.24(\mathrm{~m}, 1 \mathrm{H}), 7.28-7.31$ (m, 4H), 7.33 (d, $J$ $=8.3 \mathrm{~Hz}, 2 \mathrm{H}), 7.87(\mathrm{~d}, J=8.3 \mathrm{~Hz}, 2 \mathrm{H}) ;{ }^{13} \mathrm{C}$ NMR $(126 \mathrm{MHz}$, $\left.\mathrm{CDCl}_{3}\right) \delta 21.6,22.6,34.3,35.0,36.1,61.8,121.9\left(\mathrm{q}, J_{\mathrm{CF}}=6 \mathrm{~Hz}\right)$, $123.5\left(\mathrm{q}, J_{\mathrm{CF}}=277 \mathrm{~Hz}\right), 126.5,127.0,128.3,128.6,129.4,138.2$, $140.60\left(\mathrm{q}, J_{\mathrm{CF}}=28 \mathrm{~Hz}\right), 140.63,143.6,188.8 ;{ }^{19} \mathrm{~F}$ NMR $(470$ $\mathrm{MHz}, \mathrm{CDCl}_{3}$ ) $\delta 100.0$ (br s, 3F); HRMS (ESI+): $\mathrm{MNa}^{+}$, found 472.1538. $\mathrm{C}_{24} \mathrm{H}_{26} \mathrm{~F}_{3} \mathrm{NNaO}_{2} \mathrm{~S}$ requires 472.1534 .

\subsection{5. (Z)-2-(Cyclohexylmethylene)-4-(difluoromethylene)-3,3- dimethyltetrahydrofuran (3a)}

To a DMF $(1.7 \mathrm{~mL})$ solution of ketone $1 \mathrm{a}(44 \mathrm{mg}, 0.17 \mathrm{mmol})$ was added a toluene solution of KHMDS $(0.50 \mathrm{M}, 0.33 \mathrm{~mL}, 0.17$ mmol) at $0{ }^{\circ} \mathrm{C}$. After stirring at $110{ }^{\circ} \mathrm{C}$ for $1 \mathrm{~h}$, the reaction was quenched with phosphate buffer $(\mathrm{pH} 7)$ at room temperature. The organic materials were extracted with diethyl ether three times. The combined organic extracts were washed with water and brine and dried over $\mathrm{Na}_{2} \mathrm{SO}_{4}$. After the solvent was removed under reduced pressure, the residue was purified by column chromatography (pentane/diethyl ether $=10 / 1)$ to give $\mathbf{3 a}(21 \mathrm{mg}$, $53 \%$ ) as a colorless oil; [Found: $\mathrm{C}, 69.37 ; \mathrm{H}, 8.34 . \mathrm{C}_{14} \mathrm{H}_{20} \mathrm{~F}_{2} \mathrm{O}$ requires C, 69.40; H, 8.32\%]; IR (neat) v 2924, 2850, 1772, 1689 , $1448,1271,1244,1057,1016,928,889,789,594,540 \mathrm{~cm}^{-1} ;{ }^{1} \mathrm{H}$ NMR $\left(500 \mathrm{MHz}, \mathrm{CDC1}_{3}\right) \delta$ 0.95-1.08 (m, 2H), 1.10-1.20 (m, $1 \mathrm{H}), 1.22-1.36(\mathrm{~m}, 2 \mathrm{H}), 1.32(\mathrm{~s}, 6 \mathrm{H}), 1.59-1.73(\mathrm{~m}, 5 \mathrm{H}), 2.25-$ $2.35(\mathrm{~m}, 1 \mathrm{H}), 4.07(\mathrm{~d}, J=8.5 \mathrm{~Hz}, 1 \mathrm{H}), 4.61\left(\mathrm{dd}, J_{\mathrm{HF}}=3.0,3.0 \mathrm{~Hz}\right.$, $2 \mathrm{H}) ;{ }^{13} \mathrm{C}$ NMR $\left(126 \mathrm{MHz}, \mathrm{CDCl}_{3}\right) \delta 26.1,26.2,27.3,33.8,34.3$, 41.0, $66.0\left(\mathrm{~d}, J_{\mathrm{CF}}=4 \mathrm{~Hz}\right), 96.0\left(\mathrm{dd}, J_{\mathrm{CF}}=19,19 \mathrm{~Hz}\right), 101.8$, 
$149.0\left(\mathrm{dd}, J_{\mathrm{CF}}=287,284 \mathrm{~Hz}\right), 161.8 ;{ }^{19} \mathrm{~F}$ NMR $(470 \mathrm{MHz}$, $\left.\mathrm{CDC}_{3}\right) \delta 68.1\left(\mathrm{~d}, J_{\mathrm{FF}}=63 \mathrm{~Hz}, 1 \mathrm{~F}\right), 76.2\left(\mathrm{~d}, J_{\mathrm{FF}}=63 \mathrm{~Hz}, 1 \mathrm{~F}\right)$.

4.26. (Z)-4-(Difluoromethylene)-3,3-dimethyl-2-(2phenylpropylidene)tetrahydrofuran ( $3 \boldsymbol{b})$

Tetrahydrofuran $\mathbf{3 b}$ was synthesized by the method described for 3a using ketone $\mathbf{1 b}$ (52 $\mathrm{mg}, 0.18 \mathrm{mmol}$ ). Purification by preparative thin-layer chromatography (heptane/ethyl acetate $=$ 15/1) gave 3b (14 mg, 29\%) as a colorless oil; [Found: C, 72.60; $\mathrm{H}$, 6.97. $\mathrm{C}_{16} \mathrm{H}_{18} \mathrm{~F}_{2} \mathrm{O}$ requires $\mathrm{C}, 72.71 ; \mathrm{H}, 6.86 \%$ ]; IR (neat) $v$ 2968, 2873, 1772, 1689, 1456, 1375, 1257, 1230, 1045, 1007, $758,696 \mathrm{~cm}^{-1}$; ${ }^{1} \mathrm{H}$ NMR $\left(400 \mathrm{MHz}, \mathrm{CDCl}_{3}\right) \delta 1.31(\mathrm{~d}, J=6.8 \mathrm{~Hz}$, $3 \mathrm{H}), 1.32(\mathrm{~s}, 3 \mathrm{H}), 1.37(\mathrm{~s}, 3 \mathrm{H}), 3.84(\mathrm{dq}, J=9.2,6.8 \mathrm{~Hz}, 1 \mathrm{H})$, $4.39(\mathrm{~d}, J=9.2 \mathrm{~Hz}, 1 \mathrm{H}), 4.61\left(\mathrm{ddd}, J=12.2 \mathrm{~Hz}, J_{\mathrm{HF}}=3.4,3.4 \mathrm{~Hz}\right.$ $1 \mathrm{H}), 4.65\left(\mathrm{ddd}, J=12.2 \mathrm{~Hz}, J_{\mathrm{HF}}=3.4,3.4 \mathrm{~Hz}, 1 \mathrm{H}\right), 7.14-7.18(\mathrm{~m}$, $1 \mathrm{H}), 7.22-7.30(\mathrm{~m}, 4 \mathrm{H}) ;{ }^{13} \mathrm{C}$ NMR $\left(126 \mathrm{MHz}, \mathrm{CDCl}_{3}\right) \delta 22.7$, $27.1,27.2,35.1,41.3\left(\mathrm{dd}, J_{\mathrm{CF}}=3,3 \mathrm{~Hz}\right), 66.2\left(\mathrm{~d}, J_{\mathrm{CF}}=4 \mathrm{~Hz}\right)$, $95.9\left(\mathrm{dd}, J_{\mathrm{CF}}=19,19 \mathrm{~Hz}\right), 100.9,125.6,126.8,128.2,147.5$, $149.0\left(\mathrm{dd}, J_{\mathrm{CF}}=287,284 \mathrm{~Hz}\right), 162.4 ;{ }^{19} \mathrm{~F} \mathrm{NMR}(470 \mathrm{MHz}$, $\left.\mathrm{CDC1}_{3}\right) \delta 68.3\left(\mathrm{~d}, J_{\mathrm{FF}}=63 \mathrm{~Hz}, 1 \mathrm{~F}\right), 76.4\left(\mathrm{~d}, J_{\mathrm{FF}}=63 \mathrm{~Hz}, 1 \mathrm{~F}\right)$.

\subsection{7. (Z)-4-(Difluoromethylene)-2-(2,2-dimethylpropylidene)- 3,3-dimethyltetrahydrofuran (3c)}

Tetrahydrofuran $\mathbf{3 c}$ was synthesized by the method described for 3a using ketone 1c ( $82 \mathrm{mg}, 0.35 \mathrm{mmol})$. Purification by column chromatography (pentane/diethyl ether $=10 / 1$ ) gave $\mathbf{3 c}$ (46 mg, 61\%) as a colorless oil; [Found: C, 66.67; H, 8.27. $\mathrm{C}_{12} \mathrm{H}_{18} \mathrm{~F}_{2} \mathrm{O}$ requires $\mathrm{C}, 66.64 ; \mathrm{H}, 8.39 \%$ ]; IR (neat) $v 2954,2868$, $1772,1684,1458,1362,1284,1242,1081,1041,1012,951,775$ $\mathrm{cm}^{-1} ;{ }^{1} \mathrm{H}$ NMR $\left(500 \mathrm{MHz}, \mathrm{CDCl}_{3}\right) \delta 1.08(\mathrm{~s}, 9 \mathrm{H}), 1.30(\mathrm{~s}, 6 \mathrm{H})$, $4.12(\mathrm{~s}, 1 \mathrm{H}), 4.60\left(\mathrm{dd}, J_{\mathrm{HF}}=3.4,3.4 \mathrm{~Hz}, 2 \mathrm{H}\right) ;{ }^{13} \mathrm{C}$ NMR $(126$ $\left.\mathrm{MHz}, \mathrm{CDCl}_{3}\right) \delta 27.5,30.6,30.8,42.0,66.1\left(\mathrm{~d}, J_{\mathrm{CF}}=5 \mathrm{~Hz}\right), 95.7$ $\left(\mathrm{dd}, J_{\mathrm{CF}}=20,19 \mathrm{~Hz}\right), 105.7,149.0\left(\mathrm{dd}, J_{\mathrm{CF}}=287,283 \mathrm{~Hz}\right)$, 161.6; ${ }^{19} \mathrm{~F}$ NMR $\left(470 \mathrm{MHz}, \mathrm{CDC}_{3}\right) \delta 68.5\left(\mathrm{~d}, J_{\mathrm{FF}}=65 \mathrm{~Hz}, 1 \mathrm{~F}\right)$, $76.7\left(\mathrm{~d}, J_{\mathrm{FF}}=65 \mathrm{~Hz}, 1 \mathrm{~F}\right)$.

\subsection{8. (Z)-1-(Cyclohexylmethylene)-4-(difluoromethylene)-2- oxaspiro[4.4]nonane (3g)}

Tetrahydrofuran $\mathbf{3 g}$ was synthesized by the method described for 3a using ketone $\mathbf{1 g}$ (106 $\mathrm{mg}, 0.37 \mathrm{mmol})$. Purification by column chromatography (heptane/ethyl acetate $=100 / 1$ ) gave $\mathbf{3 g}$ (43 mg, 43\%) as a colorless oil; [Found: C, 71.70; H, 8.29. $\mathrm{C}_{16} \mathrm{H}_{22} \mathrm{~F}_{2} \mathrm{O}$ requires $\mathrm{C}, 71.61 ; \mathrm{H}, 8.26 \%$ ]; IR (neat) $v 2922,2850$, 1770, 1684, 1448, 1373, 1259, 1234, 1207, 1092, 1034, 947, 889, $775 \mathrm{~cm}^{-1}$; ${ }^{1} \mathrm{H}$ NMR $\left(400 \mathrm{MHz}, \mathrm{CDCl}_{3}\right) \delta 0.96-1.05(\mathrm{~m}, 2 \mathrm{H})$, $1.11-1.20(\mathrm{~m}, 1 \mathrm{H}), 1.25-1.35(\mathrm{~m}, 2 \mathrm{H}), 1.60-1.78(\mathrm{~m}, 9 \mathrm{H}), 1.81-$ $1.88(\mathrm{~m}, 2 \mathrm{H}), 1.94-2.01(\mathrm{~m}, 2 \mathrm{H}), 2.27-2.35(\mathrm{~m}, 1 \mathrm{H}), 4.08(\mathrm{~d}, J=$ $8.8 \mathrm{~Hz}, 1 \mathrm{H}), 4.60\left(\mathrm{dd}, J_{\mathrm{HF}}=3.4,3.4 \mathrm{~Hz}, 2 \mathrm{H}\right) ;{ }^{13} \mathrm{C} \mathrm{NMR}(126$ $\left.\mathrm{MHz}, \mathrm{CDCl}_{3}\right) \delta 25.9,26.1,26.2,33.8,34.4,40.0\left(\mathrm{~d}, J_{\mathrm{CF}}=2 \mathrm{~Hz}\right)$, $50.9\left(\mathrm{dd}, J_{\mathrm{CF}}=3,3 \mathrm{~Hz}\right), 66.5\left(\mathrm{~d}, J_{\mathrm{CF}}=4 \mathrm{~Hz}\right), 96.9\left(\mathrm{dd}, J_{\mathrm{CF}}=19\right.$, $19 \mathrm{~Hz}), 102.1,148.8\left(\mathrm{dd}, J_{\mathrm{CF}}=286,283 \mathrm{~Hz}\right), 162.6 ;{ }^{19} \mathrm{~F}$ NMR $\left(470 \mathrm{MHz}, \mathrm{CDCl}_{3}\right) \delta 68.4\left(\mathrm{~d}, J_{\mathrm{FF}}=64 \mathrm{~Hz}, 1 \mathrm{~F}\right), 75.4\left(\mathrm{~d}, J_{\mathrm{FF}}=64\right.$ $\mathrm{Hz}, 1 \mathrm{~F})$.

\subsection{9. (Z)-1-(Cyclohexylmethylene)-4-(difluoromethylene)-2- oxaspiro[4.5]decane (3i)}

Tetrahydrofuran 3i was synthesized by the method described for 3a using ketone $\mathbf{1 i}(103 \mathrm{mg}, 0.34 \mathrm{mmol})$. Purification by column chromatography (heptane/ethyl acetate $=100 / 1$ ) gave $\mathbf{3 i}$ $(63 \mathrm{mg}, 66 \%)$ as a colorless oil; [Found: C, 72.41; H, 8.45. $\mathrm{C}_{17} \mathrm{H}_{24} \mathrm{~F}_{2} \mathrm{O}$ requires $\mathrm{C}, 72.31 ; \mathrm{H}, 8.57 \%$ ]; IR (neat) $v 2922,2850$, $1765,1684,1448,1255,1080,1038,997,887,771 \mathrm{~cm}^{-1} ;{ }^{1} \mathrm{H}$ NMR (400 MHz, $\left.\mathrm{CDC1}_{3}\right) \delta$ 0.99-1.12 (m, 2H), 1.14-1.21 (m, $1 \mathrm{H}), 1.26-1.32(\mathrm{~m}, 2 \mathrm{H}), 1.34-1.54(\mathrm{~m}, 1 \mathrm{H}), 1.57-1.78(\mathrm{~m}, 14 \mathrm{H})$, $2.30-2.38(\mathrm{~m}, 1 \mathrm{H}), 4.36(\mathrm{~d}, J=8.8 \mathrm{~Hz}, 1 \mathrm{H}), 4.54\left(\mathrm{dd}, J_{\mathrm{HF}}=3.2\right.$,
$3.2 \mathrm{~Hz}, 2 \mathrm{H}) ;{ }^{13} \mathrm{C}$ NMR $\left(126 \mathrm{MHz}, \mathrm{CDCl}_{3}\right) \delta 22.06,22.08,25.1$, $26.1,26.3,33.9,34.1,34.6,44.5\left(\mathrm{dd}, J_{\mathrm{CF}}=3,3 \mathrm{~Hz}\right), 65.9\left(\mathrm{~d}, J_{\mathrm{CF}}\right.$ $=4 \mathrm{~Hz}), 96.2\left(\mathrm{dd}, J_{\mathrm{CF}}=20,17 \mathrm{~Hz}\right), 105.6,149.2\left(\mathrm{dd}, J_{\mathrm{CF}}=288\right.$, $282 \mathrm{~Hz}), 160.0 ;{ }^{19} \mathrm{~F}$ NMR $\left(470 \mathrm{MHz}, \mathrm{CDC}_{3}\right) \delta 71.1\left(\mathrm{~d}, J_{\mathrm{FF}}=64\right.$ $\mathrm{Hz}, 1 \mathrm{~F}), 77.0\left(\mathrm{~d}, J_{\mathrm{FF}}=64 \mathrm{~Hz}, 1 \mathrm{~F}\right)$.

\subsection{0. (Z)-4-(Difluoromethylene)-1-(2-phenylpropylidene)-2- oxaspiro[4.5]decane (3j)}

Tetrahydrofuran $\mathbf{3} \mathbf{j}$ was synthesized by the method described for 3a using ketone 1j (104 mg, $0.32 \mathrm{mmol}$ ). Purification by preparative thin-layer chromatography (heptane/ethyl acetate = 15/1) gave 3j (69 mg, 71\%) as a pale yellow oil; [Found: C, 74.94; $\mathrm{H}, 7.37 . \mathrm{C}_{19} \mathrm{H}_{22} \mathrm{~F}_{2} \mathrm{O}$ requires $\left.\mathrm{C}, 74.97 ; \mathrm{H}, 7.29 \%\right]$; IR (neat) $v$ 2929, 2871, 1765, 1684, 1450, 1250, 1076, 997, 879, $758,696 \mathrm{~cm}^{-1}$; ${ }^{1} \mathrm{H} \mathrm{NMR}\left(400 \mathrm{MHz}, \mathrm{CDC}_{3}\right) \delta 1.33(\mathrm{~d}, J=6.8 \mathrm{~Hz}$, $3 \mathrm{H}), 1.36-1.81(\mathrm{~m}, 10 \mathrm{H}), 3.89(\mathrm{dq}, J=9.1,6.8 \mathrm{~Hz}, 1 \mathrm{H}), 4.54$ (ddd, $\left.J=12.0 \mathrm{~Hz}, J_{\mathrm{HF}}=3.2,3.2 \mathrm{~Hz}, 1 \mathrm{H}\right), 4.58$ (ddd, $J=12.0 \mathrm{~Hz}$, $\left.J_{\mathrm{HF}}=3.2,3.2 \mathrm{~Hz}, 1 \mathrm{H}\right), 4.69(\mathrm{~d}, J=9.1 \mathrm{~Hz}, 1 \mathrm{H}), 7.14-7.19(\mathrm{~m}$, $1 \mathrm{H}), 7.26-7.33(\mathrm{~m}, 4 \mathrm{H}) ;{ }^{13} \mathrm{C}$ NMR $\left(126 \mathrm{MHz}, \mathrm{CDCl}_{3}\right) \delta 22.10$, $22.10,22.9,25.1,33.98,34.04,35.5,44.7,66.0\left(\mathrm{~d}, J_{\mathrm{CF}}=4 \mathrm{~Hz}\right)$, $96.1\left(\mathrm{dd}, J_{\mathrm{CF}}=19,17 \mathrm{~Hz}\right), 104.6,125.6,126.8,128.2,147.6$, $149.2\left(\mathrm{dd}, J_{\mathrm{CF}}=289,282 \mathrm{~Hz}\right), 160.7 ;{ }^{19} \mathrm{~F} \mathrm{NMR}(470 \mathrm{MHz}$, $\left.\mathrm{CDC1}_{3}\right) \delta 71.4\left(\mathrm{~d}, J_{\mathrm{FF}}=63 \mathrm{~Hz}, 1 \mathrm{~F}\right), 77.3\left(\mathrm{~d}, J_{\mathrm{FF}}=63 \mathrm{~Hz}, 1 \mathrm{~F}\right)$.

\subsection{2-(Cyclohexylmethylene)-4-(difluoromethylene)-3,3- dimethyl-1-(4-methylbenzenesulfonyl)pyrrolidine (4a)}

To a DMF (2.1 mL) solution of imine $2 \mathbf{a}(43 \mathrm{mg}, 0.10 \mathrm{mmol})$ in was added LDA (1.0 M in THF, $0.10 \mathrm{~mL}, 0.10 \mathrm{mmol})$ at $0{ }^{\circ} \mathrm{C}$. After stirring at $110^{\circ} \mathrm{C}$ for $2 \mathrm{~h}$, the reaction was quenched with phosphate buffer $(\mathrm{pH} \mathrm{7})$ at $0{ }^{\circ} \mathrm{C}$. The organic materials were extracted with diethyl ether three times. The combined organic extracts were washed with brine and dried over $\mathrm{Na}_{2} \mathrm{SO}_{4}$. After the solvent was removed under reduced pressure, the residue was purified by preparative thin-layer chromatography (pentane/diethyl ether $=10 / 1)$ to give 4 a $(29 \mathrm{mg}, 71 \%, E / Z=$ $32 / 68$ ) as a white solid; IR (neat) $v 2925,2850,1768,1448,1360$, 1277, 1240, 1163, 1043, 895, 843, 814, 717, 665, 582, $544 \mathrm{~cm}^{-1}$; ${ }^{1} \mathrm{H}$ NMR $\left(500 \mathrm{MHz}, \mathrm{CDC1}_{3}\right) \delta$ (major) 0.95-1.05 (m, 2H), 0.99 (s, 6H), 1.12-1.22 (m, 1H), 1.25-1.34 (m, 2H), 1.63-1.73 (m, $3 \mathrm{H}), 1.75-1.81(\mathrm{~m}, 2 \mathrm{H}), 2.43(\mathrm{~s}, 3 \mathrm{H}), 2.67-2.75(\mathrm{~m}, 1 \mathrm{H}), 4.19$ $\left(\mathrm{dd}, J_{\mathrm{HF}}=3.2,3.2 \mathrm{~Hz}, 2 \mathrm{H}\right), 4.95(\mathrm{~d}, J=10.2 \mathrm{~Hz}, 1 \mathrm{H}), 7.30(\mathrm{~d}, J=$ $8.2 \mathrm{~Hz}, 2 \mathrm{H}), 7.72(\mathrm{~d}, J=8.2 \mathrm{~Hz}, 2 \mathrm{H}) ; \delta$ (minor) $1.05(\mathrm{~s}, 6 \mathrm{H})$, $1.12-1.29(\mathrm{~m}, 5 \mathrm{H}), 1.57-1.78(\mathrm{~m}, 5 \mathrm{H}), 2.22-2.31(\mathrm{~m}, 1 \mathrm{H}), 2.42$ $(\mathrm{s}, 3 \mathrm{H}), 4.35\left(\mathrm{dd}, J_{\mathrm{HF}}=3.4,3.4 \mathrm{~Hz}, 2 \mathrm{H}\right), 5.67(\mathrm{~d}, J=11.4 \mathrm{~Hz}$, $1 \mathrm{H}), 7.28(\mathrm{~d}, J=8.2 \mathrm{~Hz}, 2 \mathrm{H}), 7.67(\mathrm{~d}, J=8.2 \mathrm{~Hz}, 2 \mathrm{H}) ;{ }^{13} \mathrm{C} \mathrm{NMR}$ $\left(126 \mathrm{MHz} \mathrm{CDCl}_{3}\right) \delta$ (major) $21.5,25.7,26.1,27.1,32.9,33.5$, $37.3,48.2,94.0\left(\mathrm{dd}, J_{\mathrm{CF}}=19,19 \mathrm{~Hz}\right), 120.6,127.6,129.5,136.5$, $142.7,143.9,149.6\left(\mathrm{dd}, J_{\mathrm{CF}}=290,281 \mathrm{~Hz}\right) ;{ }^{19} \mathrm{~F} \mathrm{NMR}(470 \mathrm{MHz}$, $\left.\mathrm{CDC1}_{3}\right) \delta$ (major) $69.1\left(\mathrm{~d}, J_{\mathrm{FF}}=61 \mathrm{~Hz}, 1 \mathrm{~F}\right), 76.2\left(\mathrm{~d}, J_{\mathrm{FF}}=61 \mathrm{~Hz}\right.$, $1 \mathrm{~F}) ; \delta$ (minor) $70.2\left(\mathrm{~d}, J_{\mathrm{FF}}=60 \mathrm{~Hz}, 1 \mathrm{~F}\right), 76.5\left(\mathrm{~d}, J_{\mathrm{FF}}=60 \mathrm{~Hz}\right.$, 1F); HRMS (ESI+): $\mathrm{MNa}^{+}$, found 418.1635. $\mathrm{C}_{21} \mathrm{H}_{27} \mathrm{~F}_{2} \mathrm{NNaO}_{2} \mathrm{~S}$ requires 418.1628 .

\subsection{2-Butylidene-4-(difluoromethylene)-3,3-dimethyl-1-(4- methylbenzenesulfonyl) pyrrolidine (4d)}

Pyrrolidine 4d was synthesized by the method described for 4a using imine 2d (47 mg, $0.13 \mathrm{mmol}$ ). Purification by preparative thin-layer chromatography (hexane/ethyl acetate $=$ 5/1) gave $4 d$ (38 $\mathrm{mg}, 84 \%, E / Z=23 / 77)$ as a white solid; IR (neat) $v 2929,2873,1770,1730,1464,1334,1290,1252,1163$, 1090, 1045, 814, 667, $544 \mathrm{~cm}^{-1} ;{ }^{1} \mathrm{H}$ NMR $\left(500 \mathrm{MHz}, \mathrm{CDC}_{3}\right) \delta$ (major) $0.92(\mathrm{t}, J=7.1 \mathrm{~Hz}, 3 \mathrm{H}), 1.04(\mathrm{~s}, 6 \mathrm{H}), 1.37-1.45(\mathrm{~m}, 2 \mathrm{H})$, 2.31-2.37 (m, 2H), $2.43(\mathrm{~s}, 3 \mathrm{H}), 4.18\left(\mathrm{dd}, J_{\mathrm{HF}}=3.2,3.2 \mathrm{~Hz}, 2 \mathrm{H}\right)$, $5.14(\mathrm{t}, J=7.0 \mathrm{~Hz}, 1 \mathrm{H}), 7.30(\mathrm{~d}, J=7.9 \mathrm{~Hz}, 2 \mathrm{H}), 7.73(\mathrm{~d}, J=7.9$ $\mathrm{Hz}, 2 \mathrm{H}) ; \delta$ (minor) 0.93 (t, $J=7.1 \mathrm{~Hz}, 3 \mathrm{H}), 1.09$ (s, 6H), $1.37-$ 
$1.45(\mathrm{~m}, 2 \mathrm{H}), 2.08-2.14(\mathrm{~m}, 2 \mathrm{H}), 2.44(\mathrm{~s}, 3 \mathrm{H}), 4.34\left(\mathrm{dd}, J_{\mathrm{HF}}=\right.$ $3.4,3.4 \mathrm{~Hz}, 2 \mathrm{H}), 5.77(\mathrm{t}, J=8.0 \mathrm{~Hz}, 1 \mathrm{H}), 7.28-7.30(\mathrm{~m}, 2 \mathrm{H})$, $7.68(\mathrm{~d}, J=8.1 \mathrm{~Hz}, 2 \mathrm{H}) ;{ }^{13} \mathrm{C} \mathrm{NMR}\left(126 \mathrm{MHz}, \mathrm{CDCl}_{3}\right) \delta$ (major) $13.9,21.5,22.3,24.0,26.0,36.6,48.3\left(\mathrm{~d}, J_{\mathrm{CF}}=3 \mathrm{~Hz}\right), 90.9(\mathrm{~d}$, $\left.J_{\mathrm{CF}}=14 \mathrm{~Hz}\right), 127.2,129.8,136.1,143.8,157.5\left(\mathrm{dd}, J_{\mathrm{CF}}=280\right.$, $280 \mathrm{~Hz}) ;{ }^{19} \mathrm{~F}$ NMR $\left(470 \mathrm{MHz}, \mathrm{CDC1}_{3}\right) \delta$ (major) $69.3\left(\mathrm{~d}, J_{\mathrm{FF}}=\right.$ $61 \mathrm{~Hz}, 1 \mathrm{~F}), 76.3\left(\mathrm{~d}, J_{\mathrm{FF}}=61 \mathrm{~Hz}, 1 \mathrm{~F}\right) ; \delta$ (minor) $70.1\left(\mathrm{~d}, J_{\mathrm{FF}}=60\right.$ $\mathrm{Hz}, 1 \mathrm{~F}), 76.5$ (d, $\left.J_{\mathrm{FF}}=60 \mathrm{~Hz}, 1 \mathrm{~F}\right)$; HRMS (ESI+): $\mathrm{MNa}^{+}$, found 378.1320. $\mathrm{C}_{18} \mathrm{H}_{23} \mathrm{~F}_{2} \mathrm{NNaO}_{2} \mathrm{~S}$ requires 378.1315.

\subsection{4-(Difluoromethylene)-3,3-dimethyl-2-(2- \\ phenylethylidene)-1-(4-methylbenzenesulfonyl)pyrrolidine (4e)}

Pyrrolidine 4e was synthesized by the method described for $4 \mathbf{a}$ using imine $2 \mathrm{e}(41 \mathrm{mg}, 0.097 \mathrm{mmol})$. Purification by preparative thin-layer chromatography (pentane/diethyl ether $=5 / 1$ ) gave $4 \mathbf{e}$ (30 mg, 76\%, E/Z = 24/76) as a white solid; [Found: C, 65.53; H, 5.96; N, 3.28. $\mathrm{C}_{22} \mathrm{H}_{23} \mathrm{~F}_{2} \mathrm{NO}_{2} \mathrm{~S}$ requires $\mathrm{C}, 65.49 ; \mathrm{H}, 5.75 ; \mathrm{N}$, $3.47 \%$ ]; IR (neat) $v 2979,2927,1728,1714,1454,1331,1290$, 1252, 1161, 1090, 1057, 814, 700, 667, $552 \mathrm{~cm}^{-1} ;{ }^{1} \mathrm{H}$ NMR (500 $\left.\mathrm{MHz}, \mathrm{CDC1}_{3}\right) \delta$ (major) 1.07 (s, 6H), $2.43(\mathrm{~s}, 3 \mathrm{H}), 3.74$ (d, $J=$ $6.9 \mathrm{~Hz}, 2 \mathrm{H}), 4.23\left(\mathrm{dd}, J_{\mathrm{HF}}=3.2,3.2 \mathrm{~Hz}, 2 \mathrm{H}\right), 5.34(\mathrm{t}, J=6.9 \mathrm{~Hz}$, $1 \mathrm{H}), 7.19-7.22(\mathrm{~m}, 3 \mathrm{H}), 7.29-7.36(\mathrm{~m}, 4 \mathrm{H}), 7.76(\mathrm{~d}, J=8.3 \mathrm{~Hz}$, $2 \mathrm{H}) ; \delta$ (minor) $1.21(\mathrm{~s}, 6 \mathrm{H}), 2.42(\mathrm{~s}, 3 \mathrm{H}), 3.50(\mathrm{~d}, J=8.3 \mathrm{~Hz}, 2 \mathrm{H})$, $4.40\left(\mathrm{dd}, J_{\mathrm{HF}}=3.3,3.3 \mathrm{~Hz}, 2 \mathrm{H}\right), 5.92(\mathrm{t}, J=8.3 \mathrm{~Hz}, 1 \mathrm{H}), 7.12(\mathrm{~d}$, $J=7.4 \mathrm{~Hz}, 2 \mathrm{H}), 7.19-7.22$ (m, 3H), 7.29-7.36 (m, 2H), 7.59 (d, $J$ $=8.2 \mathrm{~Hz}, 2 \mathrm{H}) ;{ }^{13} \mathrm{C} \mathrm{NMR}\left(126 \mathrm{MHz}, \mathrm{CDCl}_{3}\right) \delta$ (major) 21.6, 27.0, $35.5,43.3\left(\mathrm{dd}, J_{\mathrm{CF}}=3,3 \mathrm{~Hz}\right), 48.2\left(\mathrm{~d}, J_{\mathrm{CF}}=5 \mathrm{~Hz}\right), 93.8\left(\mathrm{dd}, J_{\mathrm{CF}}=\right.$ 22, $19 \mathrm{~Hz}), 118.3,126.0,127.8,128.42,128.42,129.7,136.1$, $141.2,144.3,145.4,149.8\left(\mathrm{dd}, J_{\mathrm{CF}}=288,284 \mathrm{~Hz}\right) ;{ }^{19} \mathrm{~F}$ NMR $\left(470 \mathrm{MHz}, \mathrm{CDCl}_{3}\right) \delta$ (major) $69.6\left(\mathrm{~d}, J_{\mathrm{FF}}=60 \mathrm{~Hz}, 1 \mathrm{~F}\right), 76.6(\mathrm{~d}$, $\left.J_{\mathrm{FF}}=60 \mathrm{~Hz}, 1 \mathrm{~F}\right) ; \delta$ (minor) $70.7\left(\mathrm{~d}, J_{\mathrm{FF}}=60 \mathrm{~Hz}, 1 \mathrm{~F}\right), 76.9\left(\mathrm{~d}, J_{\mathrm{FF}}\right.$ $=60 \mathrm{~Hz}, 1 \mathrm{~F})$.

\subsection{3-(Difluoromethylene)-3a-methyl-1-(4-}

methylbenzenesulfonyl)-2,3,3a,4,5,6-hexahydro-1H-indole (4f)

Pyrrolidine $4 \mathbf{f}$ was synthesized by the method described for $\mathbf{4 a}$ using a mixture of imine $\mathbf{2 f}$ and its enamine form $(60 \mathrm{mg}, 0.17$ mmol). Purification by preparative thin-layer chromatography (pentane/diethyl ether $=10 / 1)$ gave $\mathbf{4 f}(52 \mathrm{mg}, 93 \%)$ as a white solid; IR (neat) $v$ 2941, 1776, 1682, 1599, 1454, 1362, 1282, $1165,1092,814,669,544 \mathrm{~cm}^{-1} ;{ }^{1} \mathrm{H}$ NMR $\left(500 \mathrm{MHz}, \mathrm{CDC1}_{3}\right) \delta$ $0.60(\mathrm{~s}, 3 \mathrm{H}), 1.50-1.59(\mathrm{~m}, 2 \mathrm{H}), 1.68-1.70(\mathrm{~m}, 1 \mathrm{H}), 1.93-1.95$ (m, 1H), 2.09-2.17 (m, 2H), $2.41(\mathrm{~s}, 3 \mathrm{H}), 4.05$ (ddd, $J=13.2,4.7$, $3.3 \mathrm{~Hz}, 1 \mathrm{H}), 4.20(\mathrm{dd}, J=13.2,3.0 \mathrm{~Hz}, 1 \mathrm{H}), 5.70(\mathrm{t}, J=3.8 \mathrm{~Hz}$, $1 \mathrm{H}), 7.29(\mathrm{~d}, J=8.2 \mathrm{~Hz}, 2 \mathrm{H}), 7.72(\mathrm{~d}, J=8.2 \mathrm{~Hz}, 2 \mathrm{H}) ;{ }^{13} \mathrm{C} \mathrm{NMR}$ $\left(126 \mathrm{MHz} \mathrm{CDCl}_{3}\right) \delta 17.2,21.5,23.1,23.5\left(\mathrm{~d}, J_{\mathrm{CF}}=2 \mathrm{~Hz}\right), 31.6$ $\left(\mathrm{d}, J_{\mathrm{CF}}=4 \mathrm{~Hz}\right), 40.5\left(\mathrm{dd}, J_{\mathrm{CF}}=3,3 \mathrm{~Hz}\right), 46.5\left(\mathrm{~d}, J_{\mathrm{CF}}=5 \mathrm{~Hz}\right), 92.4$ $\left(\mathrm{dd}, J_{\mathrm{CF}}=23,18 \mathrm{~Hz}\right), 107.9,127.2,129.5,134.6,141.0,144.0$, $149.9\left(\mathrm{dd}, J_{\mathrm{CF}}=287,286 \mathrm{~Hz}\right) ;{ }^{19} \mathrm{~F}$ NMR $\left(470 \mathrm{MHz}, \mathrm{CDC1}_{3}\right) \delta$ 70.5 (dt, $J=60,4 \mathrm{~Hz}, 1 \mathrm{~F}), 75.6(\mathrm{~d}, J=60 \mathrm{~Hz}, 1 \mathrm{~F})$; HRMS (ESI+): $\mathrm{MNa}^{+}$, found 362.1006. $\mathrm{C}_{17} \mathrm{H}_{19} \mathrm{~F}_{2} \mathrm{NNaO}_{2} \mathrm{~S}$ requires 362.1002 .

\subsection{4-(Difluoromethylene)-2-(2-phenylethylidene)-2-(4- methylbenzenesulfonyl)-2-azaspiro[4.4]nonane (4h)}

Pyrrolidine 4h was synthesized by the method described for 4a using imine $\mathbf{2 h}(80 \mathrm{mg}, 0.18 \mathrm{mmol})$. Purification by preparative thin-layer chromatography (hexane/ethyl acetate $=$ $5 / 1)$ gave 4 h $(65 \mathrm{mg}, 85 \%, E / Z=18 / 82)$ as a white solid; IR (neat) $v 2958,2877,1766,1599,1452,1360,1165,1090,814$, $700 \mathrm{~cm}^{-1} ;{ }^{1} \mathrm{H}$ NMR $\left(500 \mathrm{MHz}, \mathrm{CDC1}_{3}\right) \delta$ (major) 1.59-1.69 (m, $8 \mathrm{H}), 2.43$ (s, 3H), 3.76 (d, $J=6.8 \mathrm{~Hz}, 2 \mathrm{H}), 4.20$ (br s, $2 \mathrm{H}), 5.35$ $(\mathrm{t}, J=6.8 \mathrm{~Hz}, 1 \mathrm{H}), 7.16-7.24(\mathrm{~m}, 3 \mathrm{H}), 7.30(\mathrm{~d}, J=7.6 \mathrm{~Hz}, 2 \mathrm{H})$, $7.31(\mathrm{~d}, J=8.2 \mathrm{~Hz}, 2 \mathrm{H}), 7.75(\mathrm{~d}, J=8.2 \mathrm{~Hz}, 2 \mathrm{H}) ; \delta$ (minor) $1.59-1.83(\mathrm{~m}, 8 \mathrm{H}), 2.42(\mathrm{~s}, 3 \mathrm{H}), 3.45$ (d, $J=8.3 \mathrm{~Hz}, 2 \mathrm{H}), 4.32$ (br s, 2H), 5.98 (t, $J=8.3 \mathrm{~Hz}, 1 \mathrm{H}), 7.15-7.32(\mathrm{~m}, 7 \mathrm{H}), 7.57$ (d, $J$ $=7.4 \mathrm{~Hz}, 2 \mathrm{H}) ;{ }^{13} \mathrm{C}$ NMR $\left(126 \mathrm{MHz}, \mathrm{CDCl}_{3}\right) \delta$ (major) 21.6, 25.9, $35.7,40.2,48.9\left(\mathrm{~d}, J_{\mathrm{CF}}=4 \mathrm{~Hz}\right), 53.6,95.1\left(\mathrm{~d}, J_{\mathrm{CF}}=18 \mathrm{~Hz}\right), 119.3$, $126.0,128.1,128.4,128.5,129.6,136.0,141.3,144.2,146.6$, $149.6\left(\mathrm{dd}, J_{\mathrm{CF}}=270,266 \mathrm{~Hz}\right) ;{ }^{19} \mathrm{~F}$ NMR $\left(470 \mathrm{MHz}, \mathrm{CDC}_{3}\right) \delta$ (major) $69.9\left(\mathrm{~d}, J_{\mathrm{FF}}=60 \mathrm{~Hz}, 1 \mathrm{~F}\right), 76.2\left(\mathrm{~d}, J_{\mathrm{FF}}=60 \mathrm{~Hz}, 1 \mathrm{~F}\right) ; \delta$ (minor) $70.4\left(\mathrm{~d}, J_{\mathrm{FF}}=59 \mathrm{~Hz}, 1 \mathrm{~F}\right), 76.3\left(\mathrm{~d}, J_{\mathrm{FF}}=59 \mathrm{~Hz}, 1 \mathrm{~F}\right)$; HRMS (ESI+): $\mathrm{MH}^{+}$, found 430.1647. $\mathrm{C}_{24} \mathrm{H}_{26} \mathrm{~F}_{2} \mathrm{NO}_{2} \mathrm{~S}$ requires 430.1652 .

\section{Acknowledgments}

This work was financially supported by JSPS KAKENHI Grant Number JP16H04105 (J.I.) in Grant-in-Aid for Scientific Research (B), JSPS KAKENHI Grant Number JP18H04234 (J.I.) in Precisely Designed Catalysts with Customized Scaffolding, and JSPS KAKENHI Grant Number JP18K05116 (T.F.) in Grant-in-Aid for Scientific Research (C). We acknowledge Tosoh Finechem Co. for a generous gift of 2-bromo-3,3,3trifluoroprop-1-ene.

\section{References and notes}

1. (a) Banks, R. E.; Smart, B. E.; Tatlow, J. C. Organofluorine Chemistry, Principles and Commercial Applications, Plenum Press, New York, 1994. (b) Uneyama, K. Organofluorine Chemistry, Blackwell Publishing, Oxford, 2006. (c) Bégué, J.-P.; Bonnet-Delpon, D. Bioorganic and Medicinal Chemistry of Fluorine, John Wiley \& Sons, Hoboken, 2008. (d) Nenajdenko, V. ed. Fluorine in Heterocyclic Chemistry vol. 1 and 2, Springer, Heidelberg, 2014. (e) Vulpetti, A.; Dalvit, C. Drug Discov. Today 2012, 17, 890-897. (f) Zhou, Y.; Wang, J.; Gu, Z.; Wang, S.; Zhu, W.; Aceña, J. L.; Soloshonok, V. A.; Izawa, K.; Liu, H. Chem. Rev. 2016, 116, 422-518. (g) Fujiwara, T.; O’Hagan, D. J. Fluorine Chem. 2014, 167, 16-29. (h) Jeschke, P. Pest Manag. Sci. 2010, 66, 10-27. (i) Babudri, F.; Farinola, G. M.; Naso, F.; Ragni, R. Chem. Commun. 2007, 1003-1022. (j) Berger, R.; Resnati, G.; Metrangolo, P.; Weber, E.; Hulliger, J. Chem. Soc. Rev. 2011, 40, 3496-3508.

2. For reviews on synthetic applications of 1,1-diflluoro-1-alkenes and 2-(trifluoromethyl)-1-alkenes, see: (a) Bonnet-Delpon, D.; Bégué, J.-P.; Lequeux, T.; Ourevitch, M. Tetrahedron 1996, 52, 59-70. (b) Chelucci, G. Chem. Rev. 2012, 112, 1344-1462. (c) Unzner, T. A.; Magauer, T. Tetrahedron Lett. 2015, 56, 877-883. (d) Zhang, X.; Cao, S. Tetrahedron Lett. 2017, 58, 375-392.

3. For addition-elimination of 1,1-diflluoro-1-alkenes, see: Ichikawa, J. Chim. Oggi 2007, 25(4), 54-57.

4. For addition-elimination of 2-(trifluoromethyl)-1-alkenes, see: Ichikawa, J. J. Synth. Org. Chem. Jpn. 2010, 68, 1175-1184. See also ref. 3 .

5. For a recent review on single activation of $\mathrm{CF}_{3}$ groups, see: Jaroschik, F. Chem. Eur. J. 2018, 24, 14572-14582.

6. For recent publications on the single $\mathrm{C}-\mathrm{F}$ activation of $\mathrm{CF}_{3}$ alkenes, see: (a) Ichitsuka, T.; Fujita, T.; Ichikawa, J. ACS Catal. 2015, 5, 5947-5950. (b) Fuchibe, K.; Hatta, H.; Oh, K.; Oki, R.; Ichikawa, J. Angew. Chem. Int. Ed. 2017, 56, 5890-5893. (c) Meißner, G.; Kretschmar, K.; Braun, T.; Kemnitz, E. Angew. Chem. Int. Ed. 2017, 56, 16338-16341. (c) Kumar, T.; Massicot, F.; Harakat, D.; Chevreux, S.; Martinez, A.; Bordolinska, K.; Preethalayam, P.; Kokkuvayil Vasu, R.; Behr, J.-B.; Vasse, J.-L.; Jaroschik, F. Chem. Eur. J. 2017, 23, 16460-16465. (d) Wu, X.; Xie, F.; Gridnev, I. D.; Zhang, W. Org. Lett. 2018, 20, 1638-1642.

7. (a) Ichikawa, J.; Wada, Y.; Okauchi, T.; Minami, T. Chem. Commun. 1997, 1537-1538. (b) Ichikawa, J.; Fujiwara, M.; Wada, Y.; Okauchi, T.; Minami, T. Chem. Commun. 2000, 1887-1888. (c) Ichikawa, J.; Wada, Y.; Fujiwara, M.; Sakoda, K. Synthesis 2002, 1917-1936.

8. (a) Nadano, R.; Iwai, Y.; Mori, T.; Ichikawa, J. J. Org. Chem 2006, 71, 8748-8754. (b) Ichikawa, J.; Iwai, Y.; Nadano, R.; Mori, T.; Ikeda, M. Chem. Asian J. 2008, 3, 393-406.

9. For Baldwin's rules, see: (a) Baldwin, J. E. J. Chem. Soc., Chem. Commun. 1976, 734-736. (b) Baldwin, J. E.; Cutting, J.; Dupont, W.; Kruse, L.; Silberman, L.; Thomas, R. C. J. Chem. Soc., Chem. Commun. 1976, 736-738. 
10. For recent reports on nucleophilic 5-endo-trig cyclization, see: (a) Tong, K.; Tu, J.; Qi, X.; Wang, M.; Wang, Y.; Fu, H.; Pittman, C. U., Jr.; Zhou, A. Tetrahedron 2013, 69, 2369-2375. (b) En, D.; Zou, G.-F.; Guo, Y.; Liao, W.-W. J. Org. Chem. 2014, 79, 44564462. (c) Johnston, C. P.; Kothari, A.; Sergeieva, T.; Okovytyy, S. I.; Jackson, K. E.; Paton, R. S.; Smith, M. D. Nat. Chem. 2015, 7, 171-177. (d) Kapoorr, R.; Singh, S. N.; Tripathi, S.; Yadav. L. D. S. Synlett 2015, 26, 1201-1206. (e) Sharma, K.; Wolstenhulme, J. R.; Painter, P. P.; Yeo, D.; Grande-Carmona, F.; Johnston, C. P.; Tantillo, D. J.; Smith, M. D. J. Am. Chem. Soc. 2015, 137, 1341413424. (f) Williams, B. M.; Trauner, D. Angew. Chem., Int. Ed. 2016, 55, 2191-2194. (g) Markwell-Heys, A. W.; George, J. H. Org. Biomol. Chem. 2016, 14, 5546-5549. (h) Xiao, T.; Li, L.; Zhou, L. J. Org. Chem. 2016, 81, 7908-7916. (i) Zhang, B.; Zhang, X.; Hao, J.; Yang, C. Org. Lett. 2017, 19, 1780-1783. (j) Hao, J.; Milcent, T.; Retailleau, P.; Soloshonok, V. A.; Ongeri, S.; Crousse, B. Eur. J. Org. Chem. 2018, 3688-3692.

11. For recent reports on radical-driven 5-endo-trig cyclization, see: (a) Ram, R. N.; Gupta, D. K.; Soni, V. K. J. Org. Chem. 2016, 81, 1665-1674. (b) Clark, A. J.; Curran, D. P.; Fox, D. J.; Ghelfi, F.; Guy, C. S.; Hay, B.; James, N.; Phillips, J. M.; Roncaglia, F.; Sellars, P. B.; Wilson, P.; Zhang, H. J. Org. Chem. 2016, 81, 5547-5565. (c) Fava, E.; Nakajima, M.; Tabak, M. B.; Rueping, M. Green Chem. 2016, 18, 4531-4535. (d) Li, J.; Hao, W.-J.; Zhou, P.; Zhu, Y.-L.; Wang, S.-L.; Tu, S.-J.; Jiang, B. RSC Adv. 2017, 7, 9693-9703. (e) Jiang, B.; Li, J.; Pan, Y.; Hao, W.; Li, G.; Tu, S. Chin. J. Chem. 2017, 35, 323-334. (f) Jansana, S.;
Coussanes, G.; Diaba, F.; Bonjoch, J. Eur. J. Org. Chem. 2017 2344-2352. (g) Wang, A.-F.; Hao, W.-J.; Zhu, Y.-L.; Li, G.; Zhou, P.; Tu, S.-J.; Jiang, B. ACS Omega 2018, 3, 1482-1491.

12. For recent reports on electrophile-driven 5-endo-trig cyclization, see: (a) Karjalainen, O. K.; Nieger, M.; Koskinen, A. M. P. Angew. Chem., Int. Ed. 2013, 52, 2551-2554. (b) Singh, P.; Panda, G. RSC Adv. 2014, 4, 2161-2166. (c) Tata, R. R.; Harmata, M. J. Org. Chem. 2015, 80, 6839-6845. (d) Fujita, T.; Watabe, Y.; Yamashita, S.; Tanabe, H.; Nojima, T.; Ichikawa, J. Chem. Lett. 2016, 45, 964-966. (e) Miao, M.; Xu, H.; Luo, Y.; Jin, M.; Chen, Z.; Xu, J.; Ren, H. Org. Chem. Front. 2017, 4, 1824-1828. (f) Raghavan, S.; Nyalata, S. Tetrahedron 2018, 74, 1071-1077. (g) Arimitsu, S.; Nakanose, M.; Gima, E. Tetrahedron Lett. 2018, 59, 887-890.

13. (a) Fujita, T.; Sakoda, K.; Ikeda, M.; Hattori, M.; Ichikawa, J. Synlett 2013, 24, 57-60. (b) Fujita, T.; Ikeda, M.; Hattori, M.; Sakoda, K.; Ichikawa, J. Synthesis 2014, 46, 1493-1505.

14. (a) Nadano, R.; Ichikawa, J. Synthesis 2006, 128-132. (b) Nadano, R.; Fuchibe, K.; Ikeda, M.; Takahashi, H.; Ichikawa, J. Chem. Asian J. 2010, 5, 1875-1883. See also ref. 8a.

15. Yamazaki, T.; Ishikawa, N. Chem. Lett. 1984, 13, 521-524. 